WHOI-98-15

Woods Hole Oceanographic Institution Capyl $^{2}$

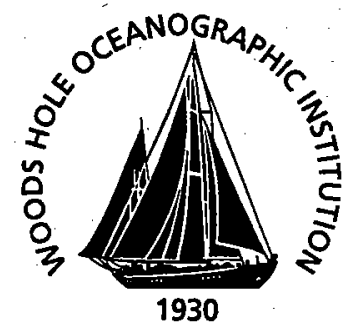

\title{
Ultimate Ocean Depth Packaging for a Digital Ring Laser Gyroscope
}

by

\author{
M. F. Bowen \\ July 30,1998
}

\section{Technical Report}

Funding was provided by the National Science Foundation under Grant No. OCE-9710512

Approved for public release; distribution unlimited.

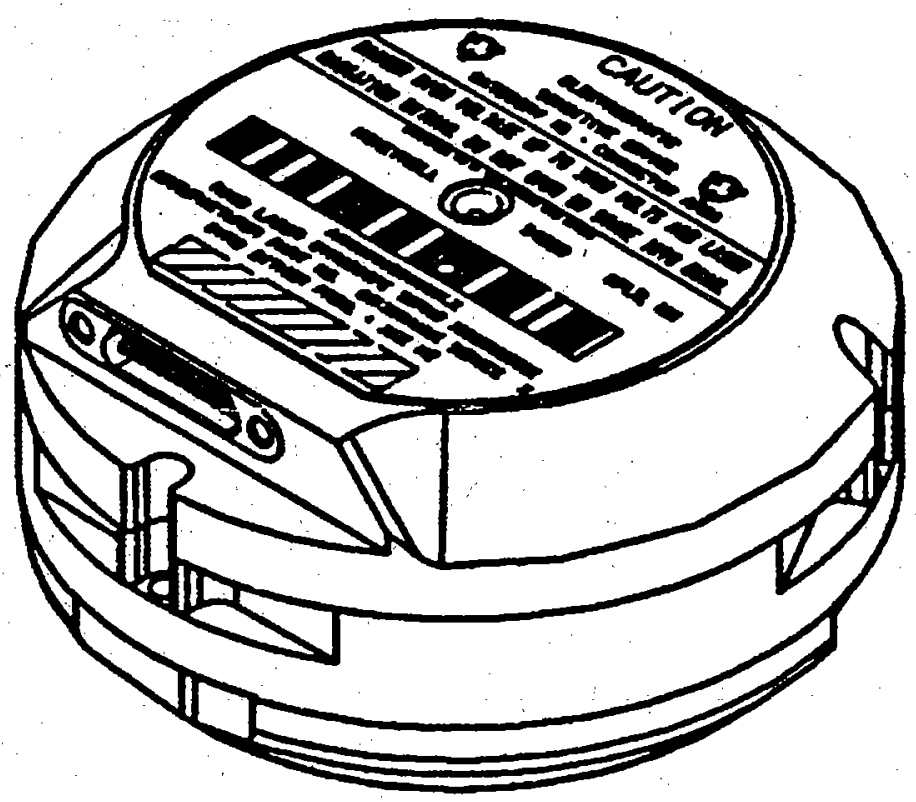




\section{WHOI-98-15}

\section{Ultimate Ocean Depth Packaging for a Digital Ring Laser Gyroscope}

by

M. F. Bowen

\section{Woods Hole Oceanographic Institution \\ Woods Hole, Massachusetts 02543}

July 30,1998

\section{Technical Report}

Funding was provided by the National Science Foundation under Grant No. OCE-9710512

Reproduction in whole or in part is permitted for any purpose of the United States Government. This report should be cited as Woods Hole Oceanog. Inst. Tech. Rept., WHOI-98-15

Approved for public release; distribution unlimited.

\section{Approved for Distribution:}

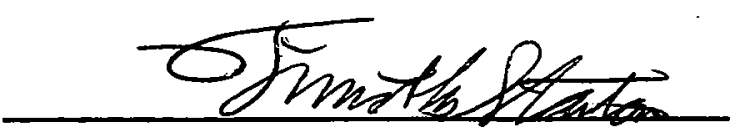

Dr. Timothy Stanton

Department of Applied Ocean Physics and Engineering 


\title{
Ultimate Ocean Depth Packaging For a Digital Ring Laser Gyroscope
}

\author{
Prepared By: \\ M.F. Bowen

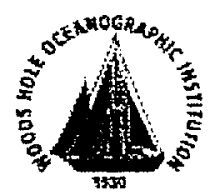

Version 1.0

30 July 1998

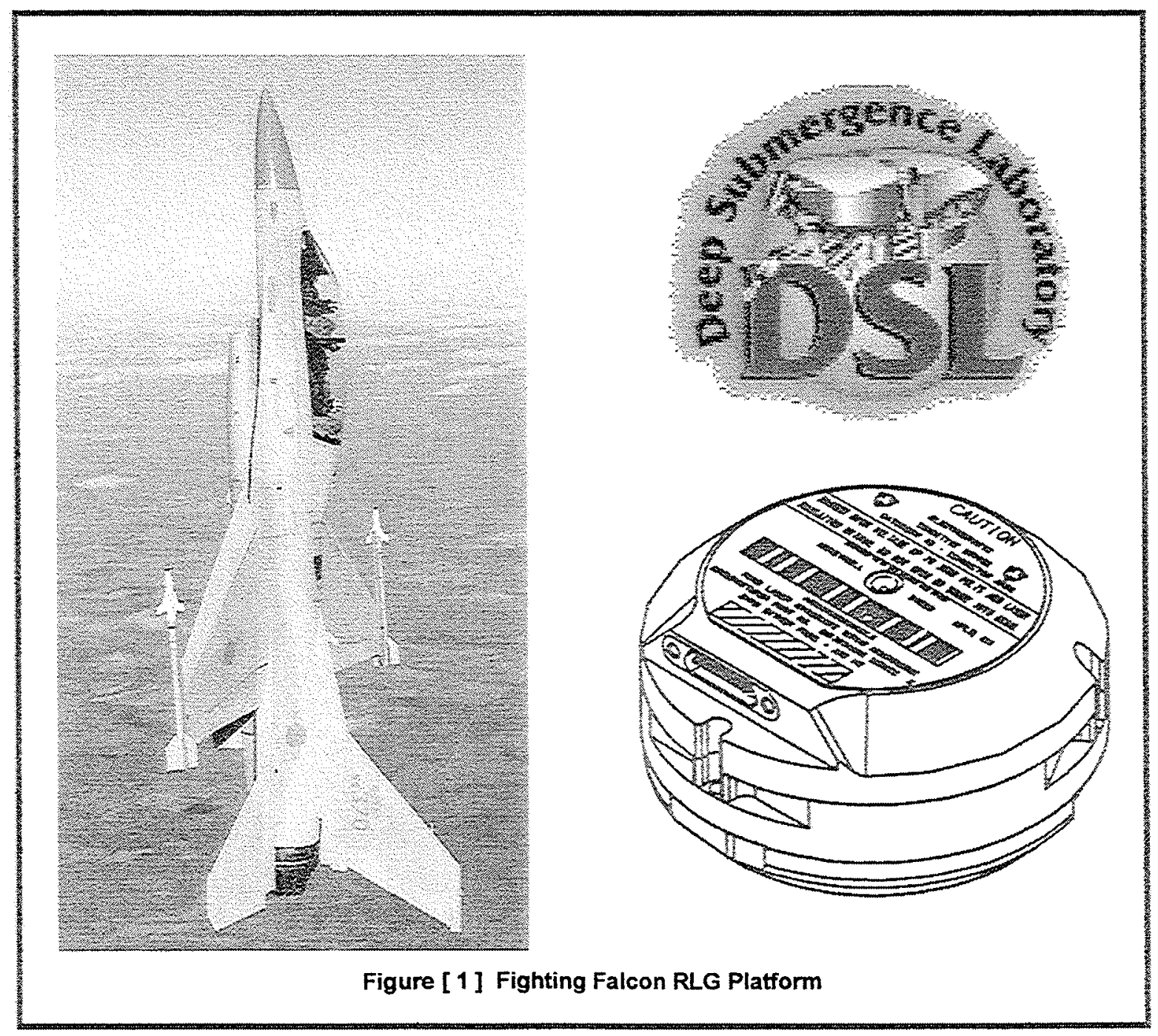




\section{Ultimate Ocean Depth Packaging for a Digital Ring Laser Gyroscope}

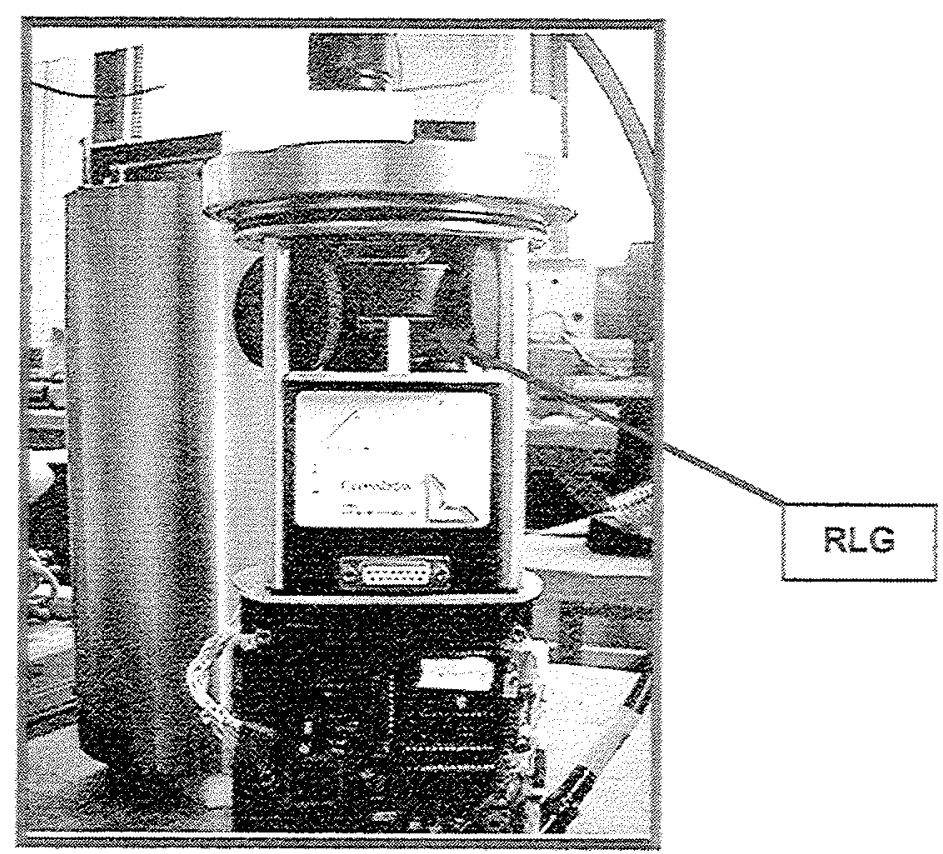

\section{Contents}

Abstract

1.0 Introduction

1.1 Package Design

1.2 Operational Advantages

2.0 RLG Deep Sea Platforms

2.1 Deep Submergence Vehicle (DSV) ALVIN

2.2 Remotely Operated Vehicle (ROV) JASON

2.3 Autonomous Underwater Vehicle (AUV) ABE

3.0 Instrument Housing

3.1 Seamless Housing Bell

3.2 Endcap and Accessories

3.2.1 Axial Registration Bracketry 7

3.2.2 Feedthrough Connectors

3.2.3 Operational Modes

3.3 Pressure Rating

4.0 Instrument Chassis

4.1 Components _ 9

4.1.1 Honeywell RLG and Anti-Vibration Mount

4.1.1.1 Power and Data

4.1.1.2 Connections

4.1.1.3 Mechanicals 10

4.1.1.4 Reliability

4.1.2 Crossbow DMU-VG

4.1.3 Axiom HC11 Single-Board Computer

4.1.4 WHOI UART PCBs

4.1.5 WHOI Power Supply Interface

4.1.6 WHOI Battery Backup

4.2 Chassis Wiring Diagram

4.3 Power Supply Interface Circuit Diagram _ 14

5.0 References

6.0 Mechanical Drawings

15-25 


\section{Fiqures}

Figure [1] Fighting Falcon RLG Platform and RLG Outline Drawing

Figure [2] Launching the ALVIN DSV

Figure [ 3 ] Launching the JASON ROV

Figure [4] Launching the ABE AUV

Figure [ 5 ] Seamless Titanium Housing Bell

Figure [ 6 ] Endcap and Axial Registering Connector Guard___ 7

Figure [ 7 ] Bracketry Drawings RLG-98-011, RLG-98-012__ 7

Figure [ 8 ] Endcap Detail, Drawing RLG-98-017___ 8

Figure [ 9 ] Pressure Statistics

Figure [ 10] RLG above DMU in Anti-Vibration Mount 9

Figure [11] Crossbow 6-Axis DMU

Figure [ 12 ] Axiom Single-Board Computer Dimensions___ 11

Figure [ 13 ] 24 C-Cell Alkaline Battery Pack__ 12

Figure [ 14$]$ Chassis Wiring Block Diagram__ 13

Figure [ 15 ] Power Supply Interface Circuit Diagram___ 14

\section{Abstract}

A Honeywell GG1320AN Digital Ring Laser Gyroscope (RLG), typically an aviation sensor, has been adapted for use as part of a navigation package rated to ocean depths of 6,000 meters. Researchers and engineers at the Deep Submergence Laboratory (DSL) of the Woods Hole Oceanographic Institution (WHOI) designed a high-density instrument package around the basic RLG. The integrated instrument is modular and field serviceable. It includes a chassis, housing, a Crossbow 6-axis dynamic measurement unit (DMU), battery backup, power regulation, support circuitry and robust interfaces. A pressure-proof titanium case and non-corroding accessories ensure that the RLG will remain unaffected by prolonged immersion in seawater. Associated mounting bracketry allow the housing to be axially registered alongside the navigation suites of various deep diving WHOI assets, or with any host platform capable of carrying a 25 pound payload. Primary RLG platforms will be the manned deep submergence vehicle ALVIN, the unmanned remotely operated vehicle JASON, and the unmanned autonomous vehicle $A B E$. As an extremely accurate yaw rate measuring device, the RLG will provide navigation data far more reliable and precise than has been available to scientists in the past. The WHOI RLG has been used successfully on one JASON cruise. (197) Keywords: submersible, navigation, gyroscope.

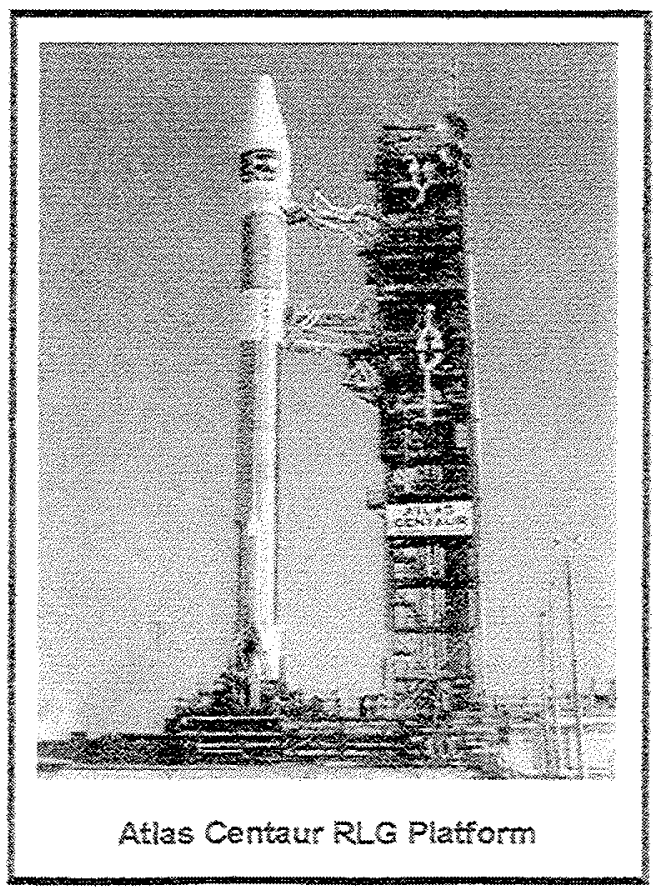




\subsection{Introduction}

A Honeywell Model GG1320AN Digital Ring Laser Gyroscope (RLG) was obtained by the Deep Submergence Operations Group (DSOG) of the Woods Hole Oceanographic Institution (WHOl) through a grant from the National Science Foundation (NSF). The RLG arrived in-house as a stand-alone unit (Figure [1]) with a military specification, software guidelines and mounting documentation. in order to use this precision navigation sensor effectively with various deep submergence assets of the National Deep Submergence Facility, a project was undertaken to design and build an "ultimate-ocean-depth" $(6,000 \mathrm{~m})$ instrumentation package, which would highlight the RLG as its primary sensor.

\subsection{Package Design}

The new RLG package had a number of assumed requirements. The design had to withstand prolonged operations at extreme ocean depths. It would experience equally stressful terrestrial environments, regularly transferred from one DSOG asset to another, shipped long distances, and handled by various operations groups around the world. A dense packing factor was desirable due to the limited payload capabilities of most unmanned underwater vehicles (ROVs and AUVS) such as JASON and ABE. The packaging challenge was undertaken by researchers and engineers at the Deep Submergence Laboratory and was completed in less than six weeks.

\subsection{Operational Advantages}

Engineers of the DSOG hope that the RLG will solve a long-standing problem with the measurement of heading on deep-diving vehicles of all kinds. True heading is essential for a variety of geophysical measurements as well as for ocean floor map-making. For example, when a sonar map is to be produced, true heading must be registered within the long-baseline navigation net, otherwise specific stations and samples will not be properly located.

Currently, a mechanical free gyro is used to measure vehicle heading (yaw rate) changes and a flux gate compass is used to measure absolute heading. (ROVs and AUVs cannot normally carry true northseeking gyroscopes because of their large size.) The smaller free gyro has good dynamic properties and performs adequately in a vehicle's servo-loop (or auto-heading) software, but a flux gate compass is too heavily filtered for servo purposes.

To date vehicle navigators have been limited to the blending of heading information from these two sensors and they have been faced with two significant problems. First, the free gyro must be initialized to acquire a "true" heading reference and the flux gate compass must be relied upon to provide that reference. However, the compass can be corrupted by local magnetic anomalies, particularly those that are found in deep volcanic terrain where heading deflections of several tens of degrees are not uncommon. Second, the mechanical gyro can drift up to several degrees per hour so it must be regularly reset. The strong possibility of resetting the gyro to a corrupted compass reference can produce incorrect heading values for the remainder of a dive.

The RLG solves both of these problems. Because the RLG drift rate is extremely low (a fraction of a degree per day), it can be initialized in concert with a support ship's true north-seeking gyro prior to vehicle deployments. Since the unit is battery-backed and has very low drift, it maintains the north heading reference and does not have to be reset throughout a typical ROV or AUV dive, which may last several days. Use of an RLG brings vehicle heading information to new levels of reliability and accuracy. 


\subsection{RLG Deep Sea Platforms}

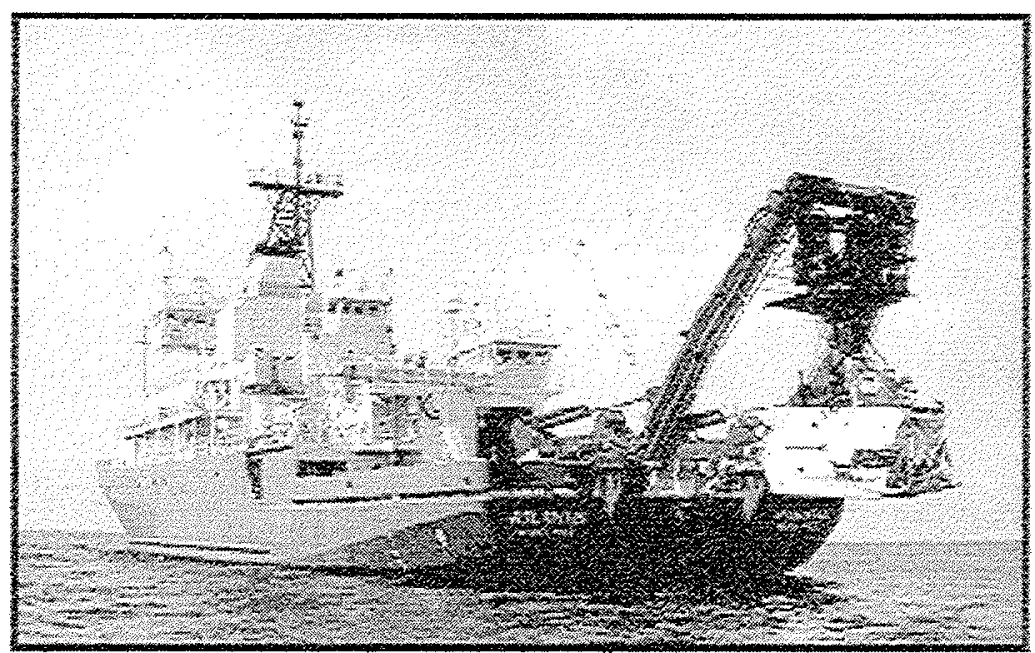

Figure [ 2 ]: Launching the ALVIN DSV

\subsection{Deep Submergence Vehicle (DSV) ALVIN}

The ALVIN will not use the pressure-proof housing provided with the package. Instead the RLG chassis and its integral titanium endcap will be mounted inside the one-atmosphere personnel sphere. $A$ lightweight plastic housing tube and plastic endcap will replace the heavier, titanium housing bell. Auxiliary connections on the plastic endcap that do not ordinarily penetrate the housing will be made available to ALVIN operators.

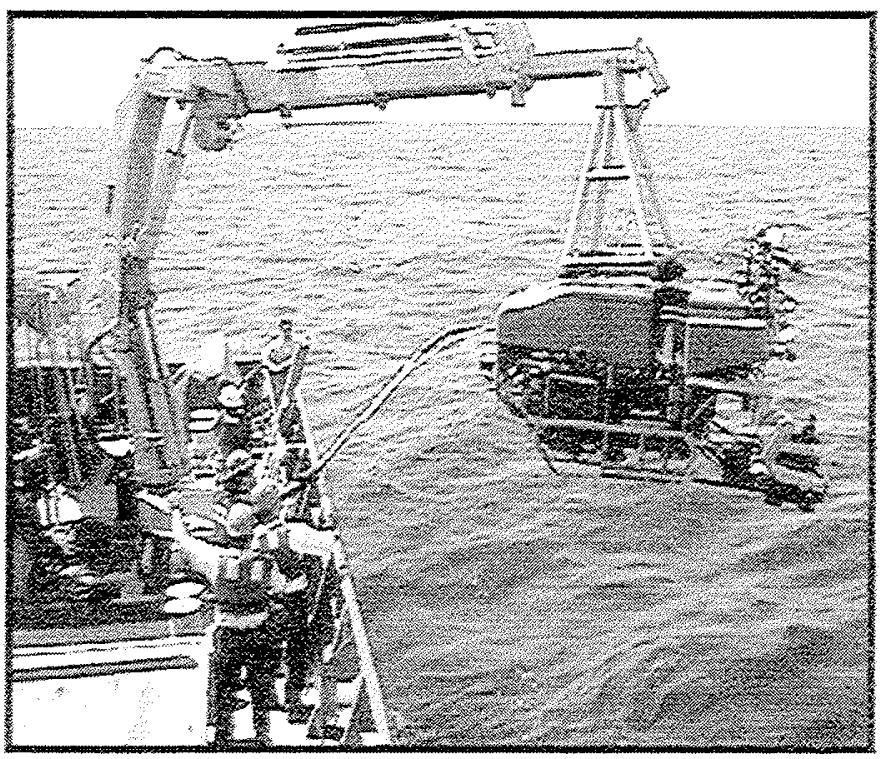

Figure [ 3 ]: Launching the JASON ROV

\subsection{Remotely Operated Vehicle (ROV) JASON}

The JASON vehicle (Figure [ 3 ]) has an existing 6-axis attitude package on board. In preliminary field operations the RLG will be registered to the planes of the JASON sensors so that complementary data may be examined. In this application the RLG in its housing will be mounted to the side of the main ROV body. 


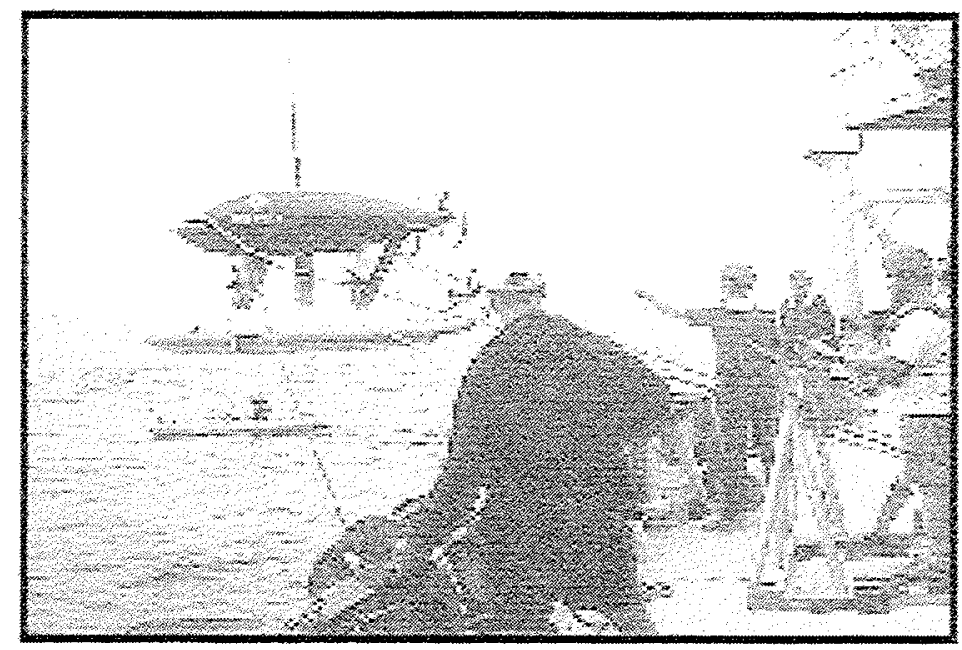

Figure [ 4 ]: Launching the ABE AUV

\subsection{Autonomous Underwater Vehicle (AUV) ABE}

The scheme for mounting the RLG onto the ABE vehicle (Figure [ 4 ]) has not yet been specified. The RLG and its housing will most probably reside on the lower of the three main pods (white).

\subsection{Instrument Housing}

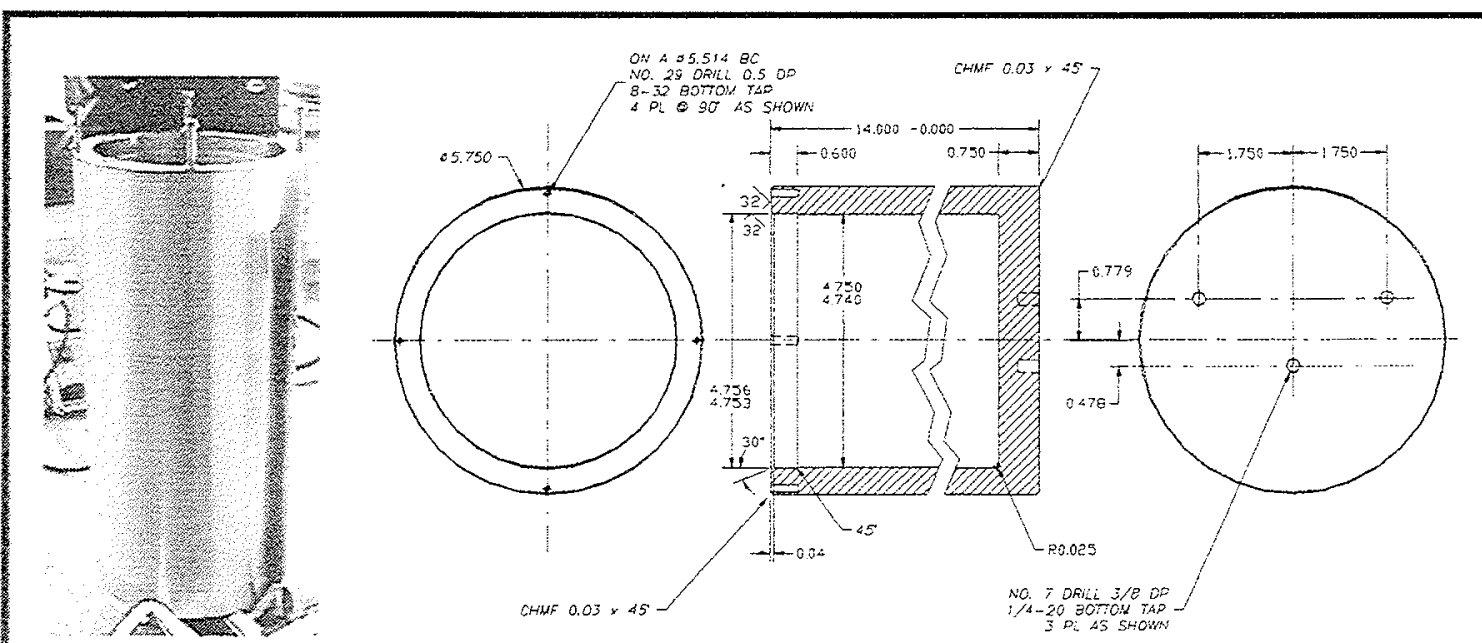

Figure [ 5 ]: Seamless Bell Housing

\subsection{Bell}

The RLG bell housing (Figure [ 5 ] and Drawing RLG-98-016) is unconventional for a grade 5 (6AL$4 \mathrm{~V}$ alloy) titanium housing that is longer than most 8 inch lathe cutting bars and that has a outside diameter greater than 4 inches. In this case the housing had to be 5.75 inches $O D, 14$ inches long, with a 0.5 -inch thick wall and a 0.75 -inch thick flat endplate to meet or exceed the depth specification.

A conventional housing would consist of two endcaps and a tube; a process involving trepanning a solid rod to produce a tube and an internal slug. However, if the package in this project were to be especially reliable, the elimination of one endcap was deemed essential. A boring process performed by a specialty machine shop was arranged rather than employing the usual trepanning. Although the slug nomally left over from the trepanning process is somewhat valuable in that it can be used to make another smaller 
housing, it was decided that the loss of the slug into shavings from the boring process was a cost-effective tradeoff.

A tube with one welded endcap was also considered, but producing a seamless bell (as shown above) in a single $\$ 600$ boring operation was logistically sound and efficiently eliminated additional \#2 endcap design time, fixturing, machining and welding.
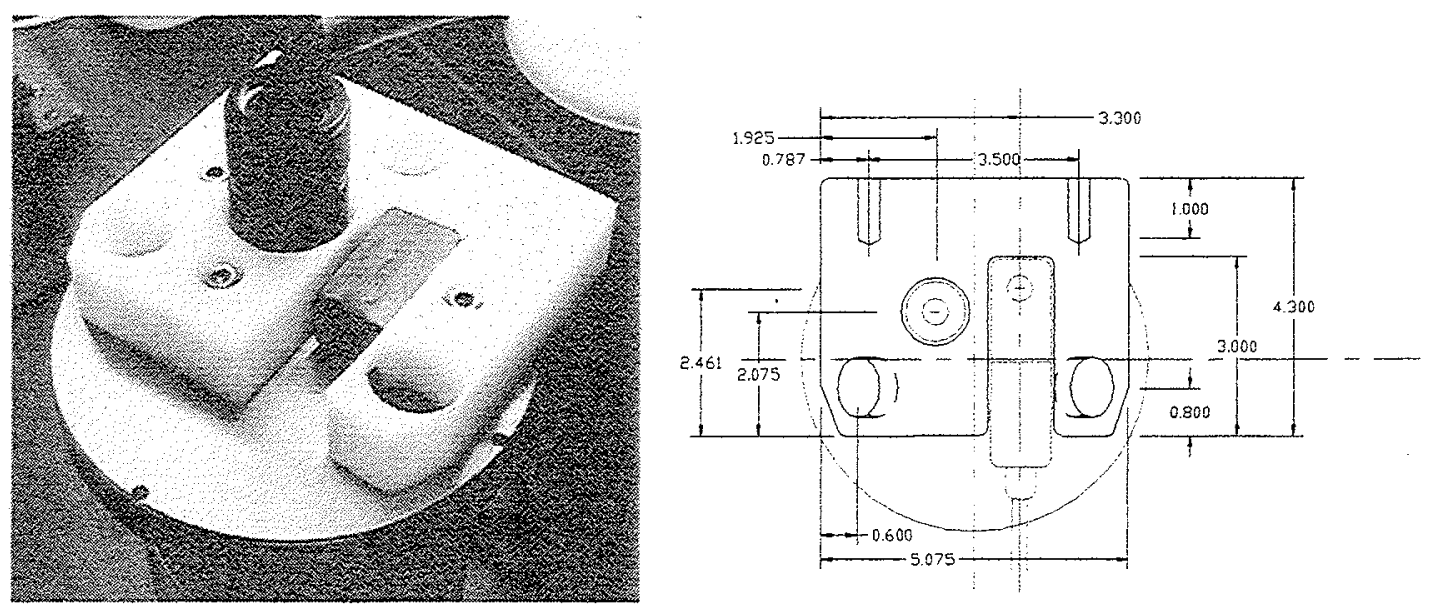

Figure 16 : Endcap and Axia Registering Connector Guard

\subsection{Endcap and Accessories}

The endcap (Figure [6] and Drawing RLG-98-017) was designed with both face and radial o-ring seais. The radial groove is beveled on the inner surface to capture and hold the seal. The endcap is secured to the bell by four 316 stainless screws. When the endcap is separated from the housing bell the entire chassis and battery pack are removed with it. This design allows the bell to be safely set-aside during trouble-shooting sessions.
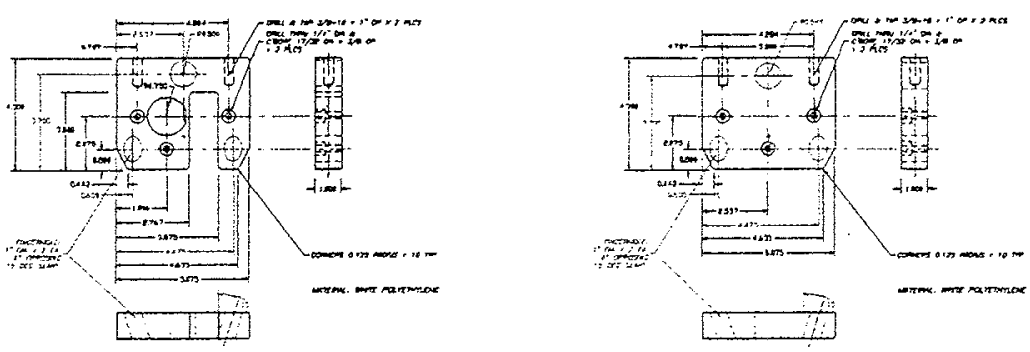

Figure [ 7 ]: Bracketry Drawings RLG-98-011, RLG-98-012

\subsubsection{Axial Registration Bracketry}

The RLG and the DMU are stacked and solidly affixed to the endcap longitudinal centerline. Both sensors are rotationally registered within half a degree of each other, and of the outboard threaded bolt patterns of both the housing bell and endcap.

The bolt patterns accept the axial registration bracketry (Figures [6] [ 7 ]), which is made of oneinch thick, white polyethylene. The bracketry transfers the planar alignment of the RLG and DMU to the host vehicle. The bracketry contains three finger holes to aid in separating the endcap from the bell. The endcap bracket surrounds the 7-pin bulkhead connector and protects it from rotational stresses. 


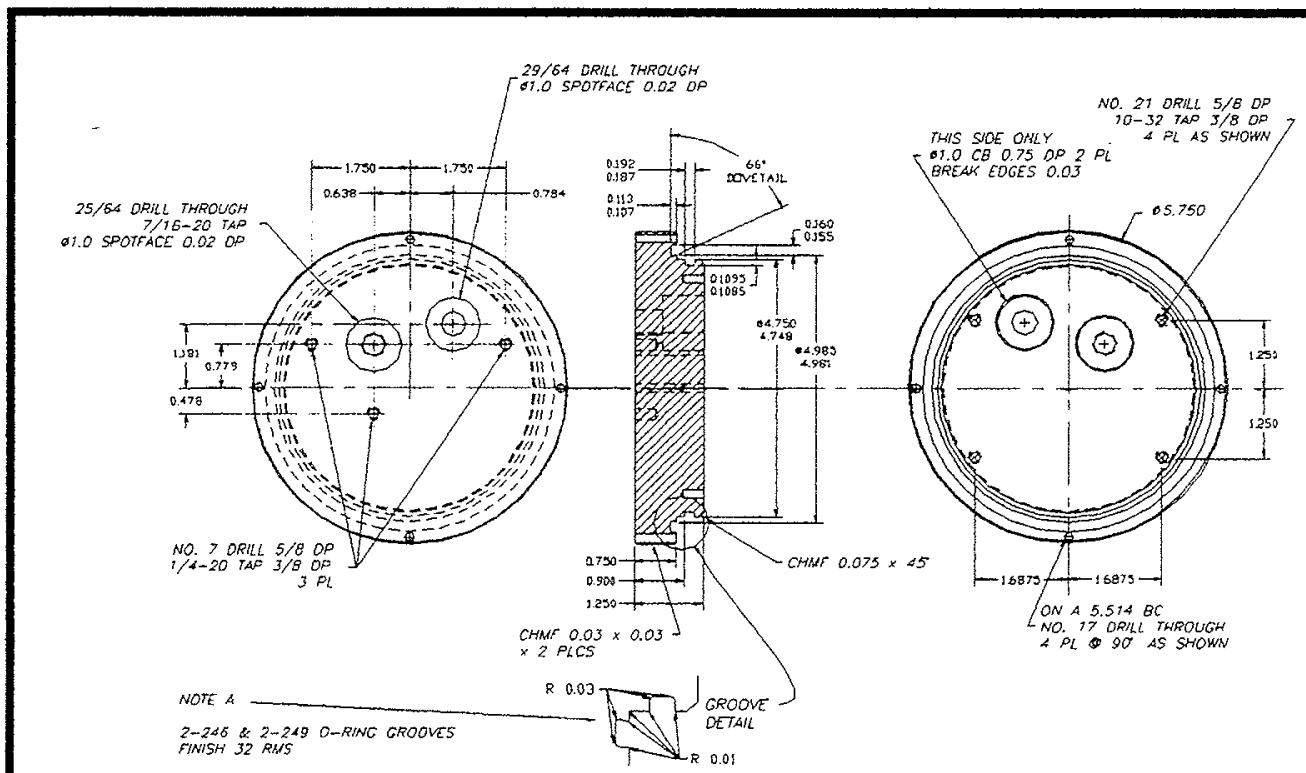

Figure [ 8 ]: Endcap Detail, Drawing RLG-98-017

\subsubsection{Feedthrough Connectors}

Two Impulse bulkhead feedthroughs were added to the endcap (Figure [ 8 ]): LPBH-7-FSISS and BH-4-MPISS. The 7-conductor, low-profile bulkhead provides external power from the platform and outputs serial information. The 4-conductor bulkhead accepted both a shorting plug and a standard dummy plug depending on the operational mode.

\subsubsection{Operational Modes}

When a standard dummy 4-pin plug is in place the unit is fully enabled (ON) using either external (vehicle) or internal (battery) power supplies. When a 4-pin shorting dummy is in place the power supplies would be interrupted. This mode is necessary to preserve battery power during long OFF periods such as during shipping or during long transit when the host vehicle may be powered down.

\subsection{Pressure Rating}

The assembled housing will fail at 19,055 psi or 12,929 meters or 42,417 feet (Figure [ 9 ]). It has been pressure tested to a working depth equivalent to 10,000 psi or 6,600 meters or 21,650 feet. The design allows for a $1.94 \mathrm{X}$ safety margin in pressure tolerance. 
Figure [ 9 ]: PRESSURE STATISTICS

TITANIUM ALLOY GAL-4V, GRADE 5

Yield Stress: $120.0000 \mathrm{Ksi}$

Poisson's ratio: 0.3250

Density: $0.1610 \mathrm{lb} / \mathrm{cu}$ in

Elastic Modulus: $17.0000 \mathrm{Mpsi}$

TUBE CONFIGURATION ALONE (External Pressure)

Inner Diameter: 4.7500 inches

Outer Diameter: 5.7500 inches

Wall Thickness: 0.5000 inches

Tube Length: 14.0000 inches

Weight in air: $18.59 \mathrm{lbs}$

Weight in water: $5.12 \mathrm{lbs}$

Failure mode: Thick wall crush

Collapse pressure: $19.0548 \mathrm{Ksi}$ (42417.0ft underwater)

Thin wall collapse mode: 2 nodes Thin Wall Collapse at: 43,604 psi $(97,064 \mathrm{ft}$ underwater)

ENDCAP CONFIGURATION ALONE (External Pressure)

Endcap Circular, Fixed

Free Diameter: 4.7500 inches

Outer Diameter: 5.7500 inches

Endcap Thickness: 0.7500 inches

Weight in air: 3.14 lbs

Weight in water: $2.41 \mathrm{lbs}$

Endcap Failure at: 24,084 psi $(53,612 \mathrm{ft}$ underwater)

TUBE PLUS ENDCAP CONFIGURATION

Tube Inner Diameter: 4.7500 inches

Tube Outer Diameter: 5.7500 inches

Tube Wall Thickness: 0.5000 inches

Tube Length: 14.0000 inches (Endcap Circular, Fixed)

Free Diameter: 4.7500 inches

Outer Diameter: 5.7500 inches

Endcap Thickness: 0.7500 inches

Combined Weight In Air: 24.86 lbs ;

in Water: 9.95 lbs

Initial failure caused by:

Tube Thick Wall Crush at: $19,055 \mathrm{psi}(42,417 \mathrm{ft}$ underwater)

\subsection{Instrument Chassis}

\subsection{Components}
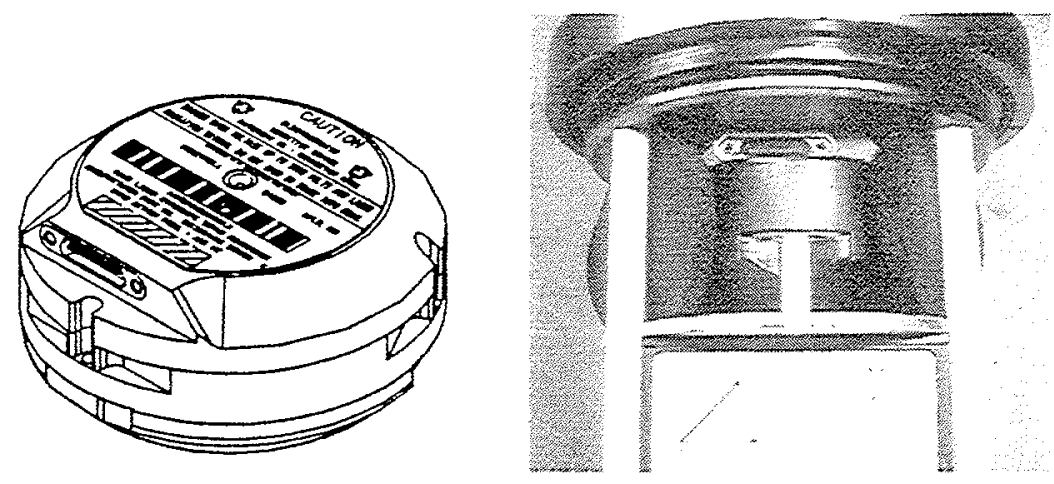

Figure [ 10 ]: RLG above DMU in Anti-Vibration Mount 


\subsubsection{Honeywell RLG and Anti-Vibration Mount}

The Honeywell Dig-Gyro RLG (Figure [ 8 ]) provides rapid angular rate measurements in a multiplexed system. Compared to other rate sensors used by the DSOG the RLG has an extremely low drift rate over time. This capability is important for navigating unmanned deep-diving platforms that may be deployed for days at a time.

\subsubsection{Power and Data}

All data from the gyro is obtained in digital form. The unit requires +15 and $+5 \mathrm{~V}$ power inputs and is mechanically self-contained. The output provides tri-stated bi-directional asynchronous serial communications at 1 MegaBaud with an $8-\mathrm{N}-1$ data byte format.

\subsubsection{Connections}

The connection for the power and signal interface to the RLG is made through a 25 pin micro $D$ pair. The RLG will mate with a MIL-C-83513/1 or a MIL-C-83513/3 connector, and the internal contacts are compatible with a 10147476-101 Honeywell bulkhead connector. Interconnect cable lengths are no longer than 3 feet per specifications.

\subsubsection{Mechanicals}

The RLG includes a laser block assembly based on an equilateral triangular 2.0 inch per leg pathlength glass-ceramic block. On the block are mounted two path-length control transducers, a readout mirror and a mirror-mounted package, which supports readout electronics and photodiodes. The block cavity is filled with a mixture of helium and neon gases. The laser block assembly is mounted within a housing that consists of an aluminum base and cover.

In order to facilitate gyro dither, the laser block mechanical interface to the housing is accomplished by means of a Super invar dither spring. Semi-rigid upper and lower chassis plate assemblies actively dampen the dither vibration that is translated to the outer case during RLG operation. Surrounding the unit with four circular open-cell foam cushions and ultra-stiff aluminum chassis rods provides additional dampening and audible noise reduction.

Also mounted within the aluminum housing is a set of electronic components, which provide the electrical interface to the gyro. The internal electronics provide the high voltage required for laser operation, control of gyro functions and readout of gyro information upon system request. This approach reduces system-level complexity and reduces requirements for electrical interface with the host WHOl system, which includes low voltage power inputs and a standard digital bus.

\subsubsection{Reliability}

The gyro case is environmentally sealed, is filled with dry nitrogen gas with a five-percent helium-4 tracer, and enclosed within a wo-piece formed nickel-iron magnetic shield. The RLG can withstand impacts of $30 \mathrm{~g}$ 's applied in any axis. It has a depth rating of 2,000 feet and an altitude rating of 70,000 feet. Its mean operating life is 100,000 hours with a mean time between failure (MTBF) of 150,000 hours or greater. The mature field random MTBF is 300,000 hours or greater. This military grade sensor should provide DSOG with years of significant service.

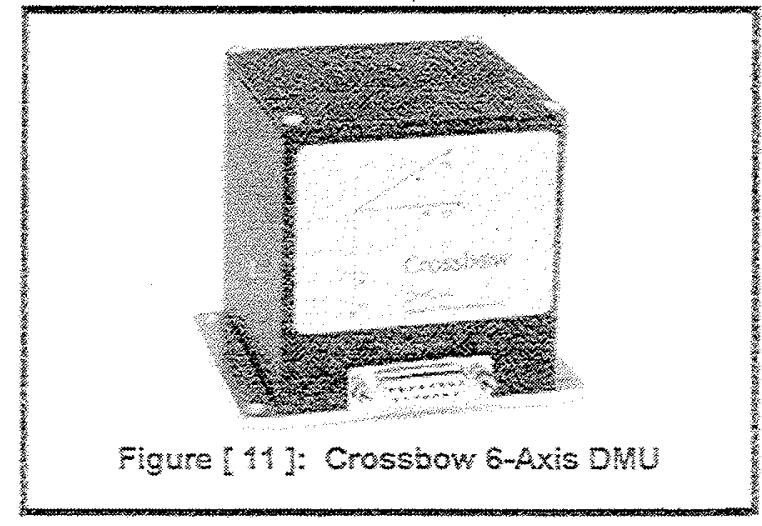




\subsubsection{Crossbow DMU}

The Crossbow DMU-VG (Figure [ 11]) is an intelligent six-axis measurement system designed for accurate $X, Y, Z$ acceleration and angle measurements in dynamic environments. The DMU outputs inertial acceleration and angular rate measurements formatted for integration with the WHOI RLG system. The unit allows for data to be requested via serial command or to be transferred continuously. The DMU outputs stabilized pitch and roll calculations for platform stabilization. Measurements taken by the DMU are complementary to data from the RLG and other navigation systems on the host platform such as the bottomlock Doppler. Other common DMU applications include GPS navigation, dynamic positioning, antennae pointing and flight data testing (Figure [ 11 ).

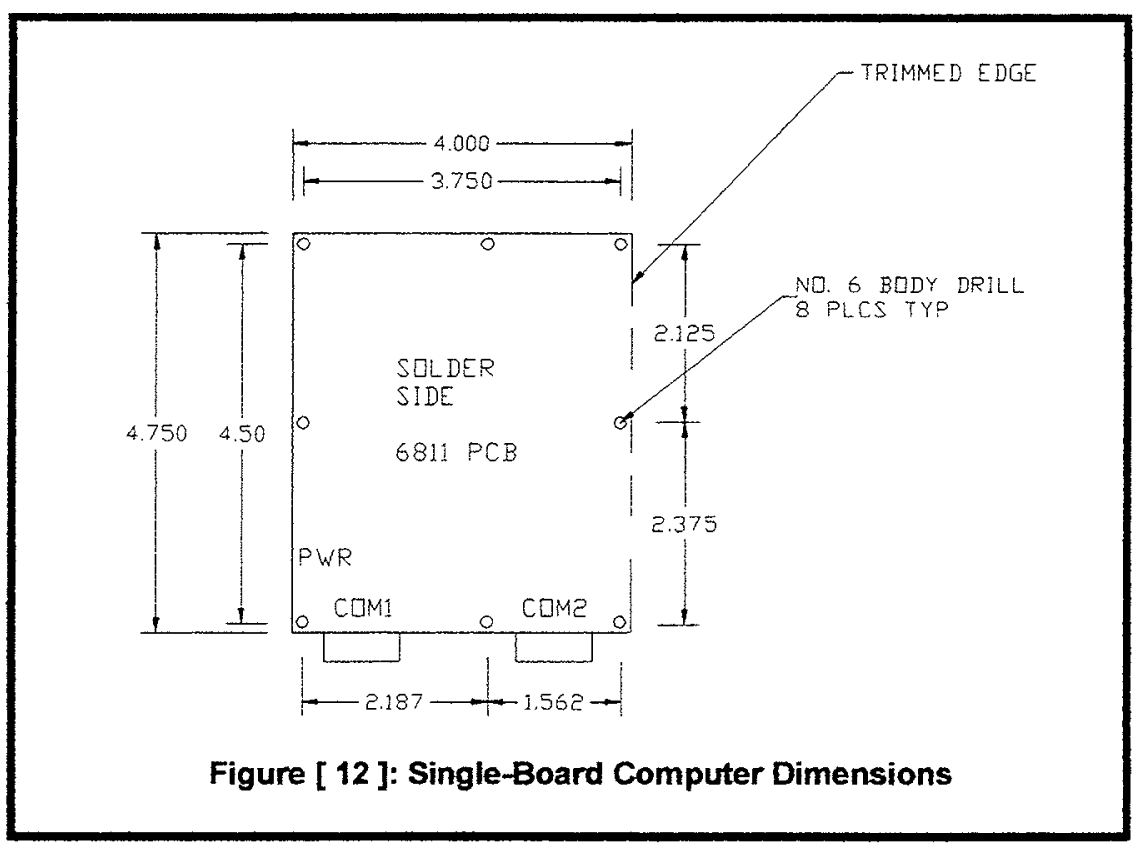

\subsubsection{Axiom HC11 Single-Board Computer}

The Axiom HC11 single-board computer (Figure [ 12 ]) is a functional development system which requires a low voltage $D C$ input and outputs to a standard serial cable. The HC11 will process the serial data from the two sensors and will compute heading and attitude information, which is then is passed on to the host vehicle over a serial interface. The Axiom is mounted in front of the RLG's backup battery pack and behind two UART and one power supply printed circuit boards. It is the largest circuit board in the package.

\subsubsection{WHOI UART PCBs}

Two universal asynchronous receiver-transmitter (UART) printed circuit boards are mounted in the RLG chassis. Each UART board contains a 16-byte FIFO buffer. The RLG UART provides an asynchronous serial interface between the RLG and the HC11. The Crossbow UART provides a similar interface to the Crossbow sensor. The RLG interface operates at 1 MegaBaud. The Crossbow interface operates at 38.4 KiloBaud. The serial interface to the host system is provided by the Axiom HC11.

\subsubsection{WHOI Power Supply Interface}

This circuit card provides an isolated 15 VDC along with an isolated 5 VDC to power the RLG. A separate isolated 15 VDC is also generated to power the Crossbow DMU-VG and the Axiom HC11 development board. The Datel switching converters employed by this circuit are exceptionally quiet and exceed the RLG's strict power supply noise specification. The power interface board has over-voltage and over-current protection on all inputs and outputs.

Detail of the WHOl circuit is shown in Figure [15]. Q1, Q2 and Q3 and their associated components provide 18 to 72 volts and the internal battery pack consisting of 24 alkaline c-cells. Q3 is the 
main power switch and it is normally biased ON via $Q 2$, which supplies a constant gate-to-source voltage of approximately 12.7 volts. When an external supply (host vehicle) is connected between pins 2 and 3 of $J 1$, Q1 is biased ON which shunts the base drive of Q2, thus turning it OFF. With Q2 off, the gate of Q3 is held via the $220 \mathrm{~K}$ resistor at the same voltage as its source, thus tuming Q3 OFF. The IN4002 blocking diode is now forward biased and routes power directly to the input of the DC to DC converters. The transition is nearly instantaneous and the $D C$ to $D C$ converter input fitter capacitors are more than adequate to hold the load while the power switches. Shorting pins 1 and 3 of 11 will also turn Q3 OFF. This provides a means of preserving the battery pack during long periods of shipping or storage.

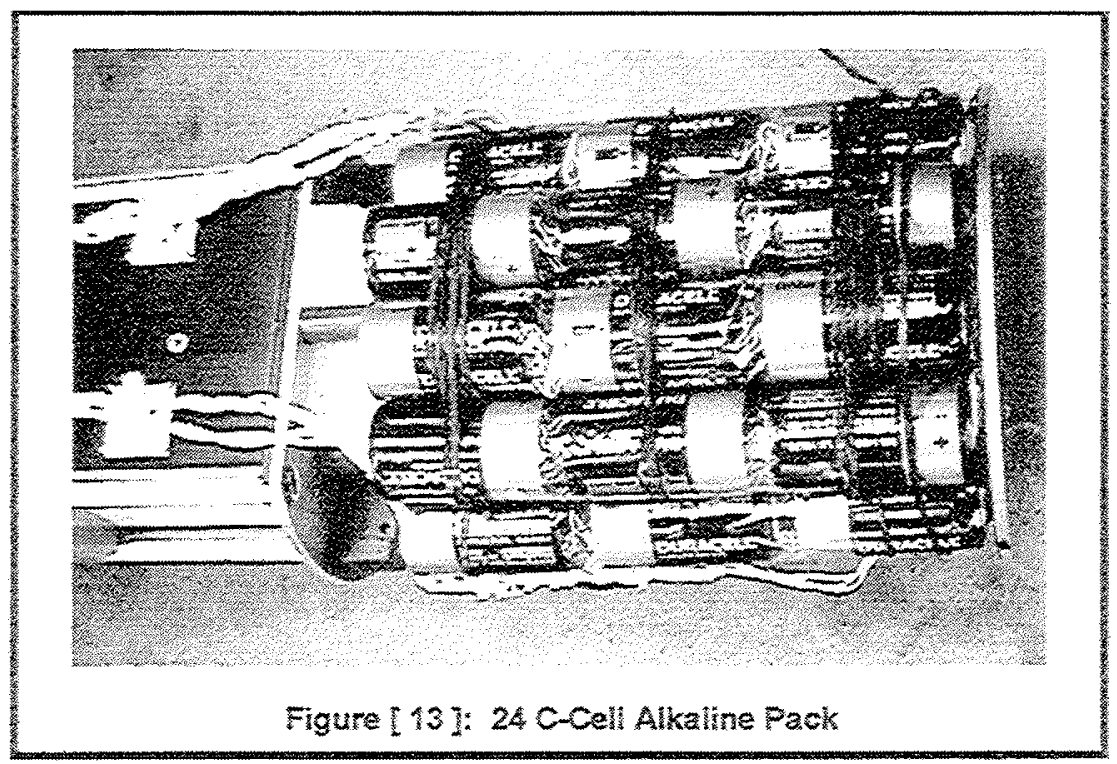

\section{1.6 Whol Eatrery Backup}

The 24-cell alkalne batey pat (Figure i 13 ) coupies the lower at guater of the houstng volume. The pack wraps around fout printed circul boards. Three isolating Phenolic tods penetrate the pack to provide stifiness and alignment The batteries are wired in paralle and produce a nominal 40 -volk supply. Which is employed when the RLG is not powered by the hos vehice during shor maintenance periods or between deployments. When the host vehicle applies extertal power to the RLO system, she power and regulation PCB automaticaly disables the internal batery pack Using a shoring piug, the operator can disable the pack manualy for long periods such as during shipping and shorage. Whenever power is interupted to the RLG, crical calbration data is also lost whoh is why the backup pack importan to the system. Pack tre is estmated a about 22 hours. ll can be repiaced with a sare pack in less than one hour.

\subsection{References}

1. Pexter, S.C. Handbook OK Oceancgraphic Encineering Materials, Rober E. Krieger Publishing Company, Malabar, Floride, 1985.

2. Detall Specifcation Document, GG1320AN Dio-Gyro Rino Laser Gyro, Specifcator Number DS341970. Honewwen Avonics Division, Minneapolis, MN, 1997.

3. Haroware Manual, QMD 1A8-HCH Sinole Board Computer, Axom Wanutaturng, Richardson, TX, 1995

4. Mouse Entemrises, Technica Manud and Connecor Selection Guide, rev 0192, Sen Diego, CA. 1997.

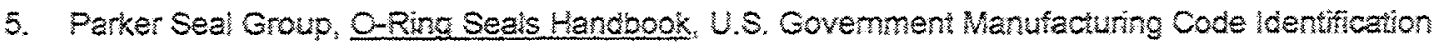
Number 02687, Lexingion, KY, 1982.

6. Pressure Housing Analysis, Under Pressure, Sotware Program, Deep Sea Power and Lght inc., San Diego, CH, 1991

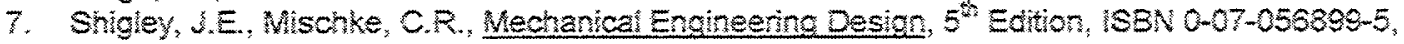

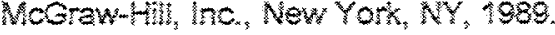

8. User Intertace Documen: GQ 320 AN Diq-Gro Ring Laser Guto, Honeywel Avionics Dision, Spectication Number E07 165-01, Cage Code 94580, Mineapois, MN, 1997. 


\subsection{Chassis Wiring Block Diagram: Figure [ 12 ]}

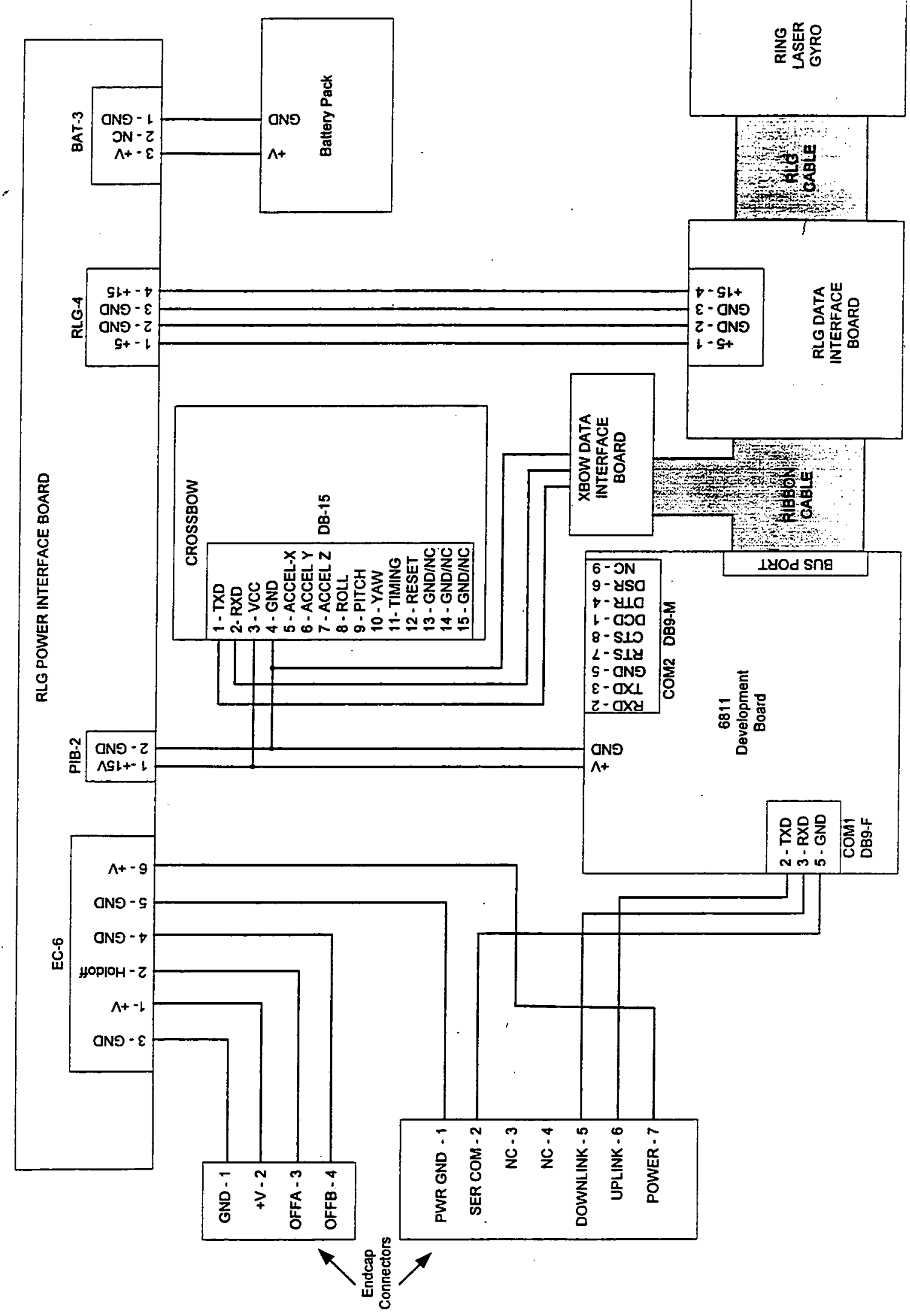




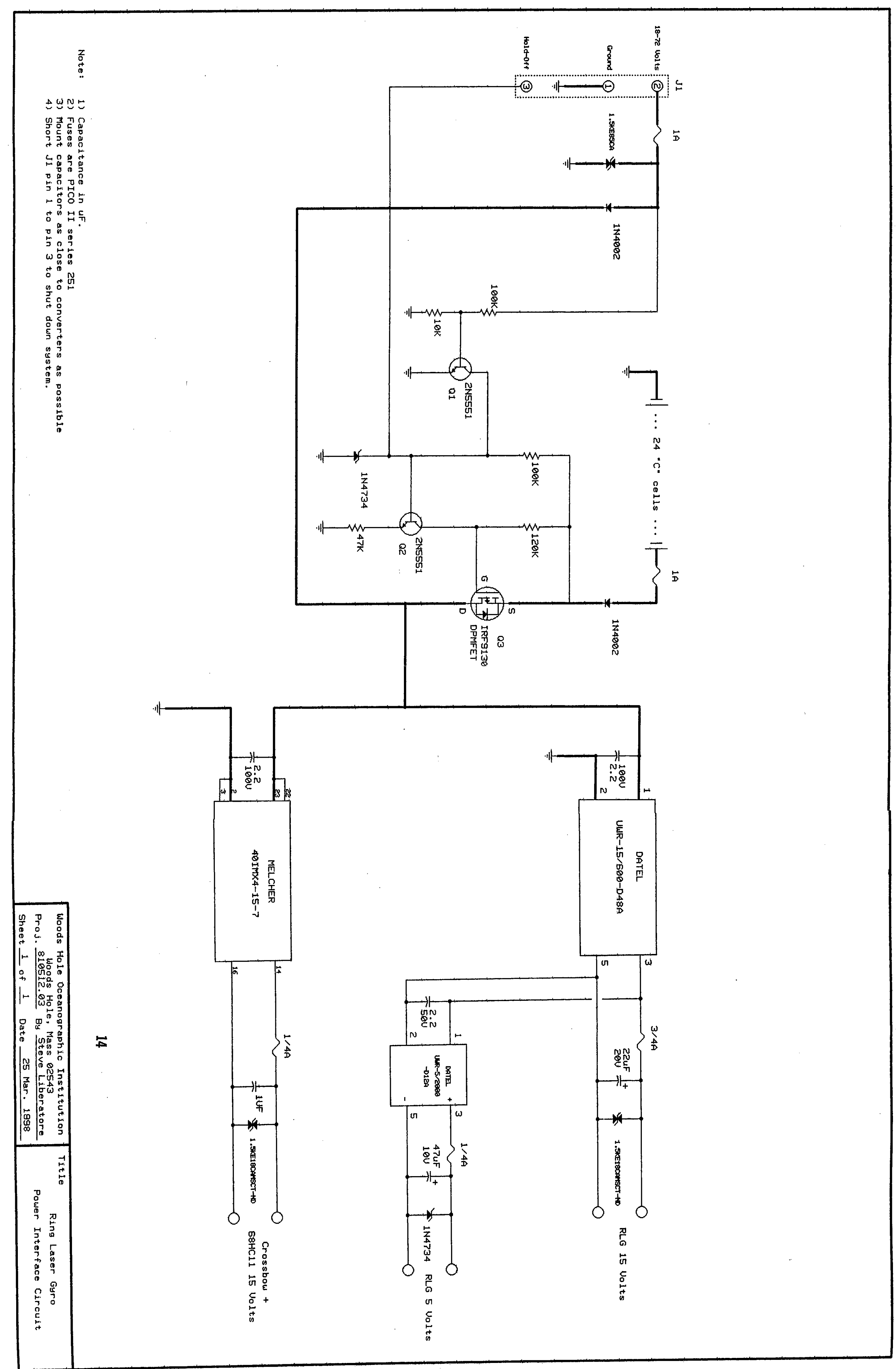




\subsection{Mechanical Drawings}

RLG-98-010

RLG-98-011

RLG-98-012

RLG-98-016

RLG-98-017

RLG-98-018

RLG-98-020

RLG-98-021

RLG-98-022

RLG-98-025

Endcap and Connector Guard

Connector Guard Detail

Housing Bell Mount

16

Housing Belf ___ 19

Endcap_L 20

Crossbow Mounting Plate___ 21

PCB Spreader__ 22

Transfer Plate 23

Sensor Stack Spacer____ 24

Battery Pack Plate___ 25

\section{Acknowledgements}

My special thanks to Tim Thiel, Steve Liberatore, Bob McCabe, Barrie Walden, Don Peters, Glenn McDonald, Albert Bradley, Jia Qin Zhang, Hanumant Singh and Dana Yoerger for their help during the performance of this project. 


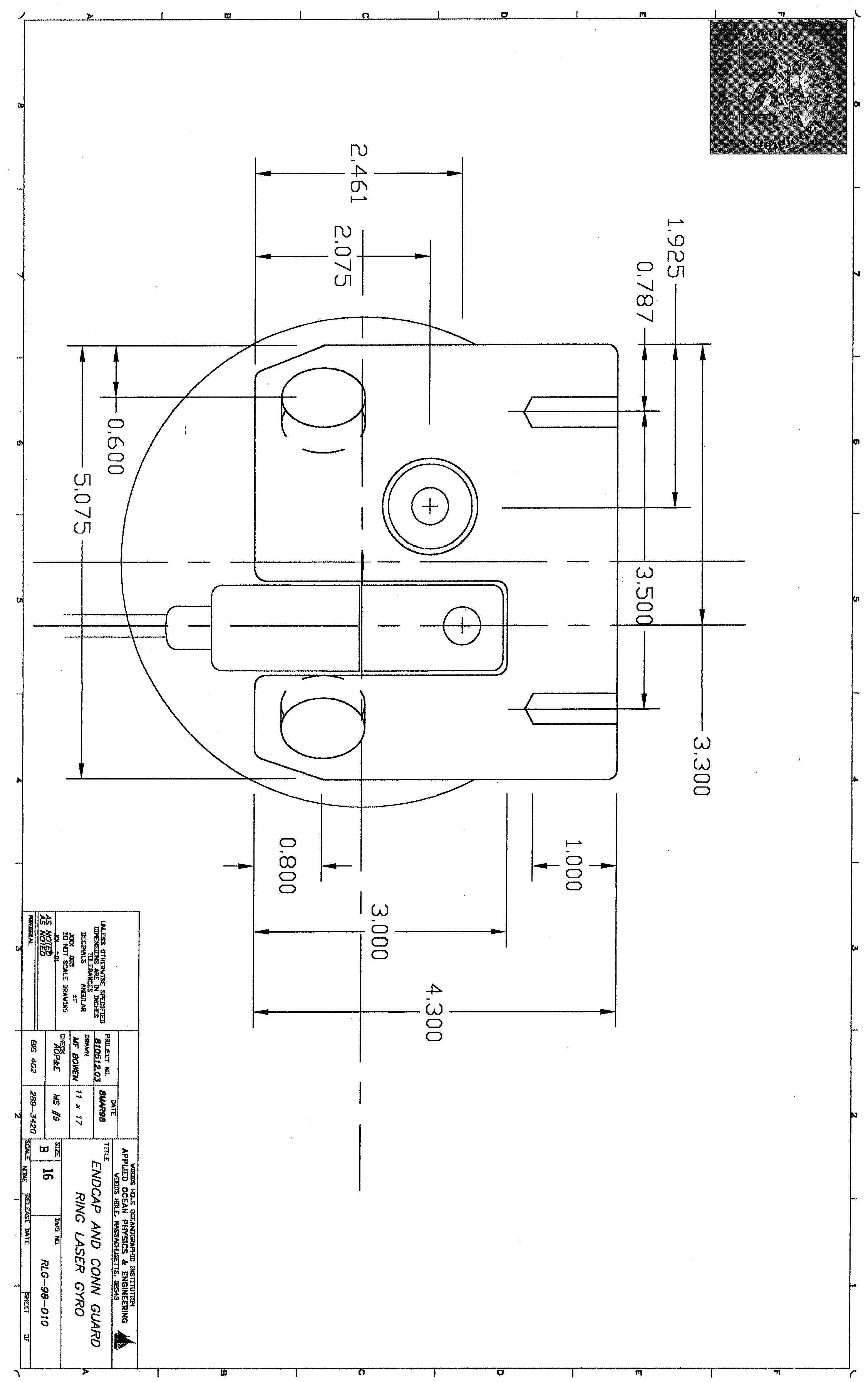




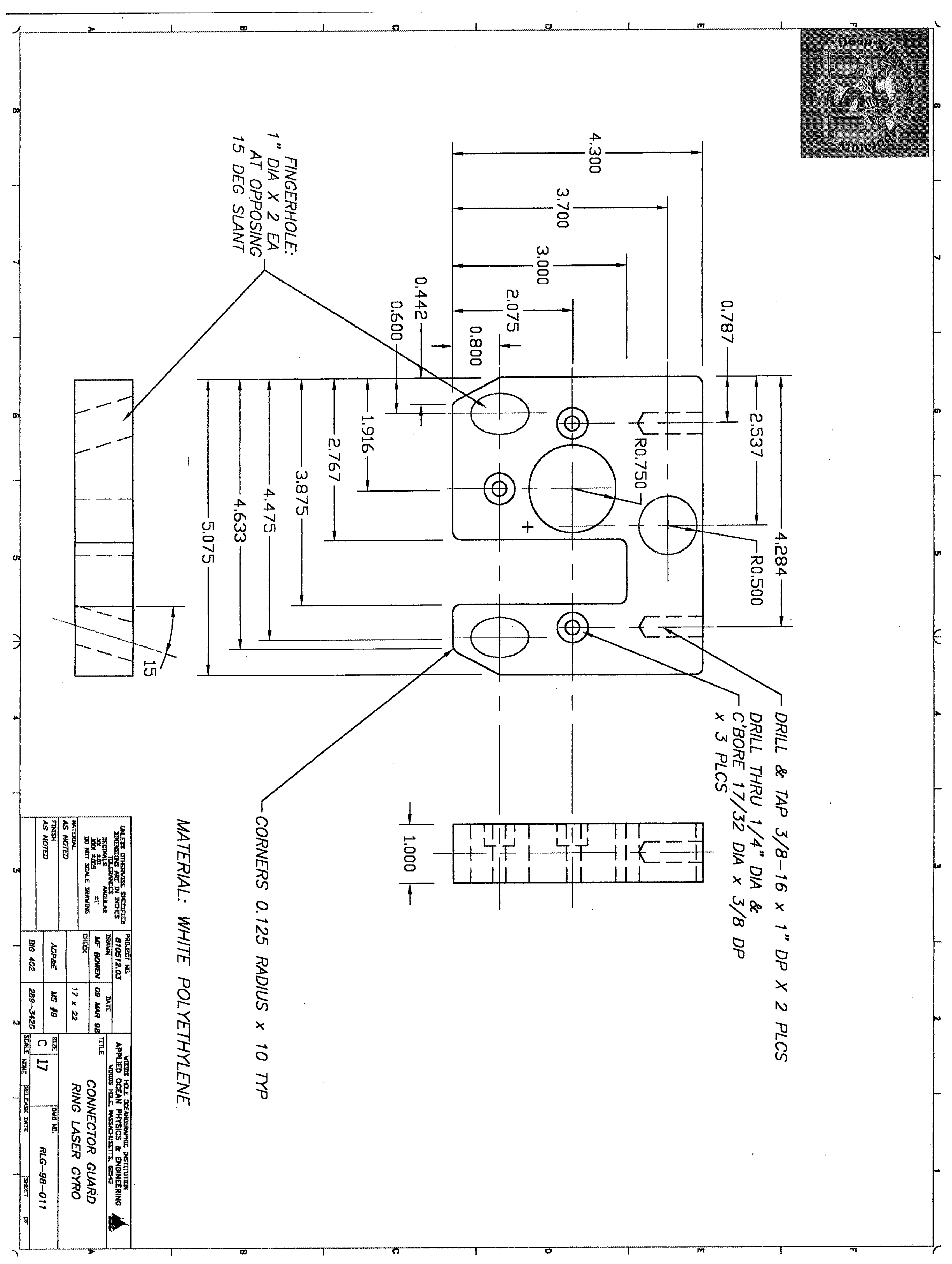




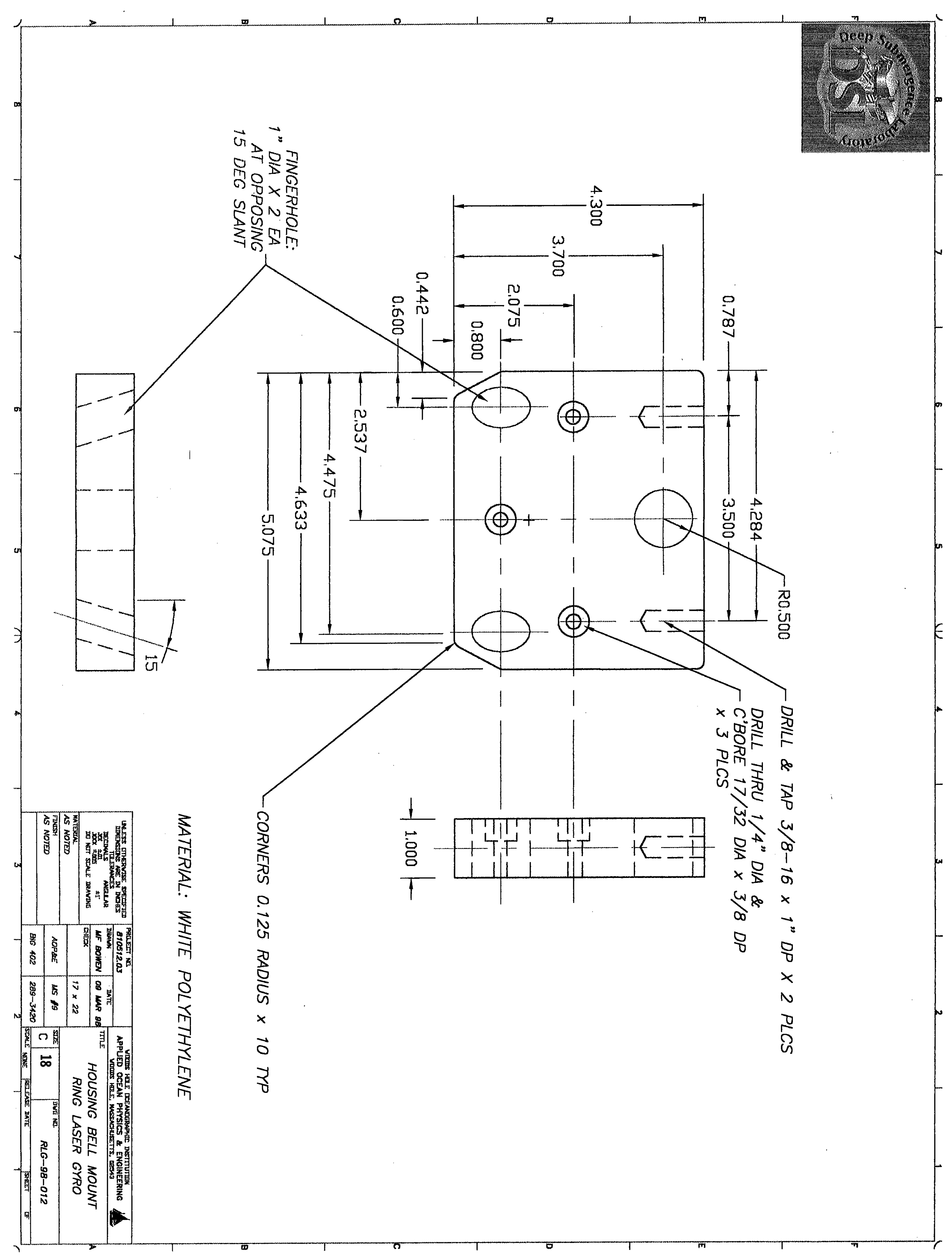




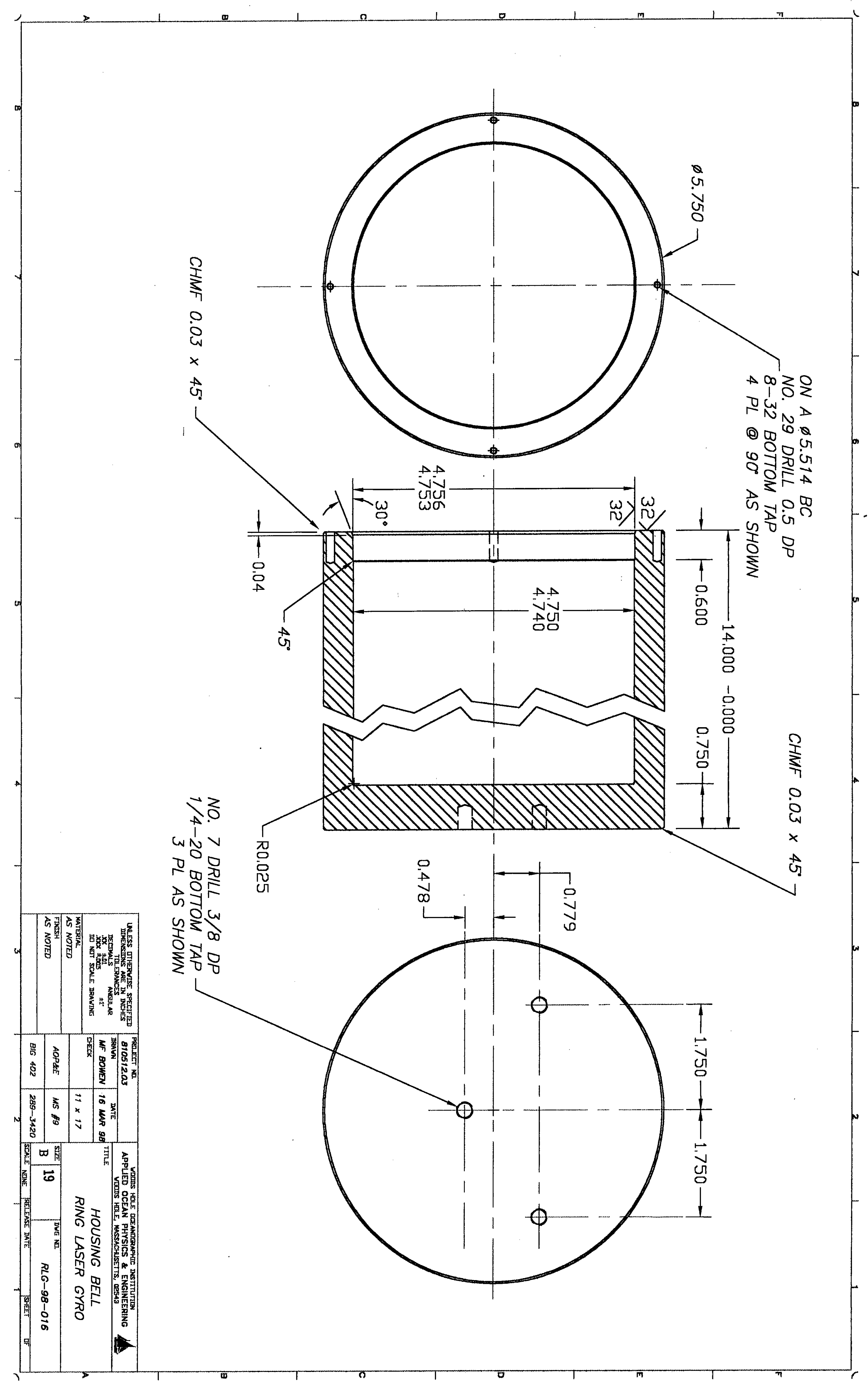




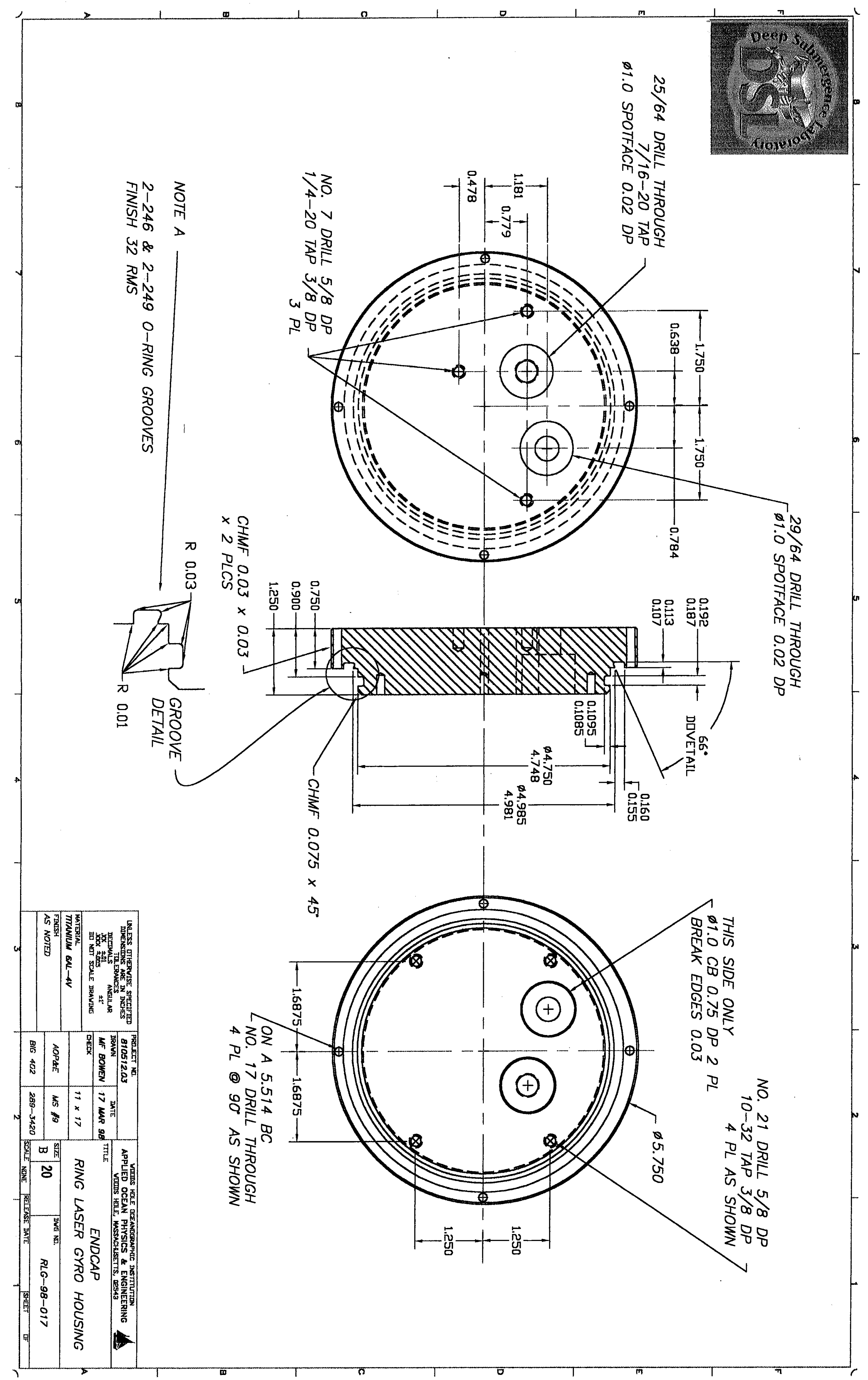


$-\begin{gathered}z \\ +\infty \\ \vdots \\ 0 \\ \frac{5}{\pi} \\ \sum\end{gathered}$

is

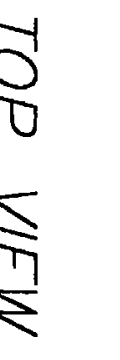

$\frac{2}{2}$

$\frac{9}{2}$

20

I

$\infty$

\begin{tabular}{l}
1 \\
1 \\
N \\
\hline
\end{tabular}

(0)

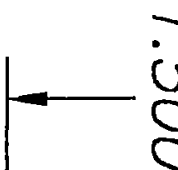

$\frac{1}{0}$

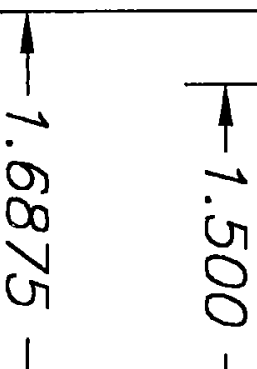

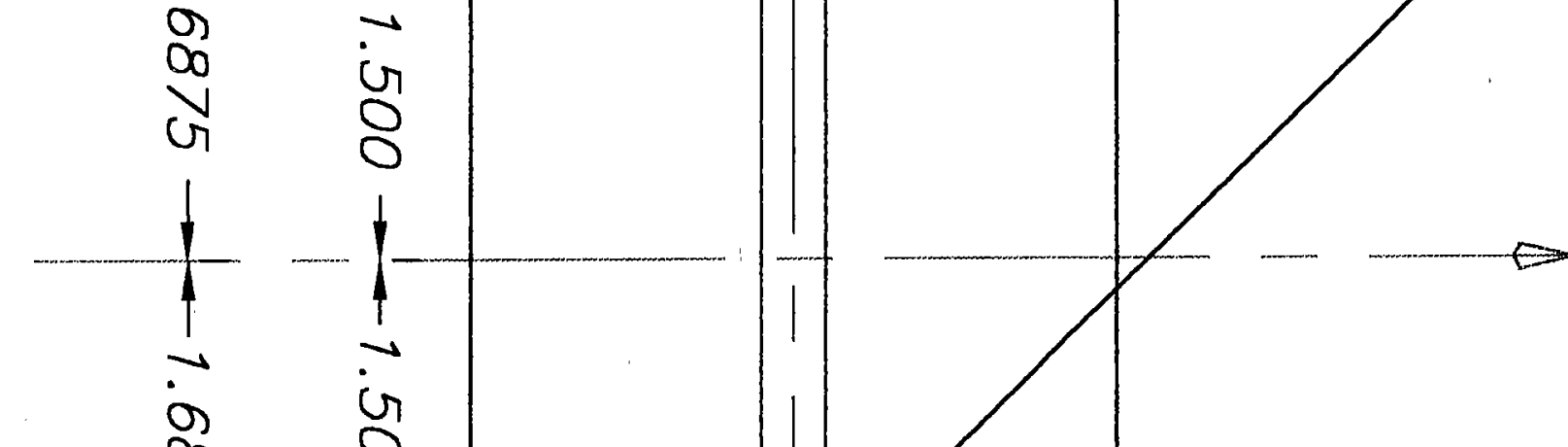

n.

Tin 6

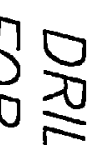

$\overrightarrow{0}$

w疋

गर्व

索

की

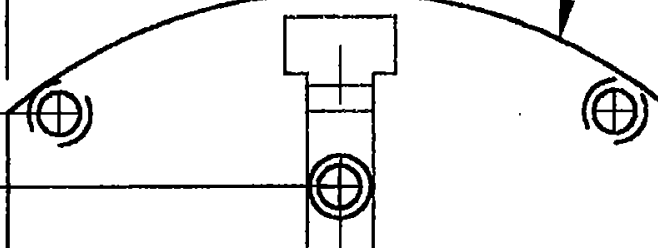

क)

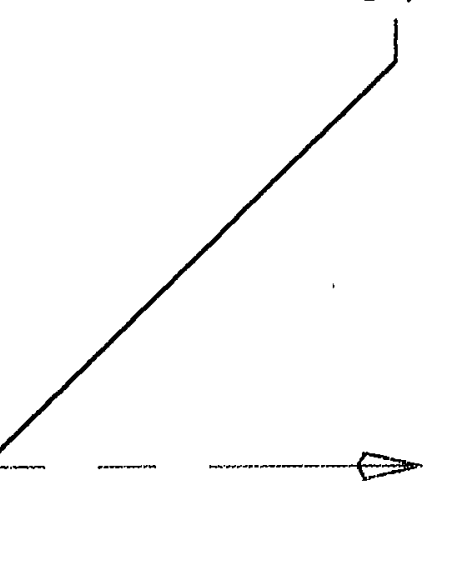

4

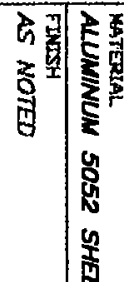

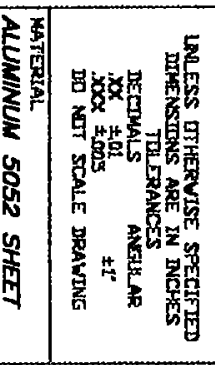

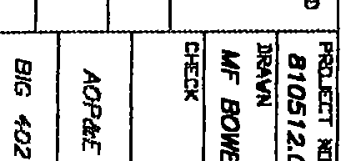

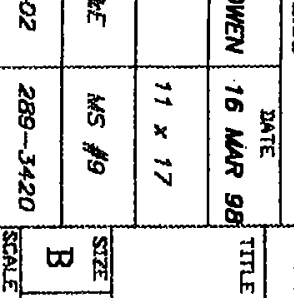

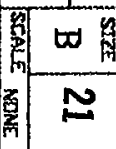

岿喜

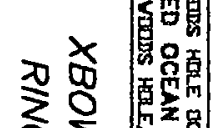

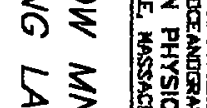

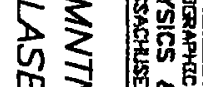

i $\overrightarrow{0}$

v

1

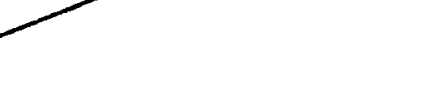

(9)

$\stackrel{2}{\frac{1}{7}}$

$\because 6$

$\prod_{\rightarrow 0} 0$

n

N

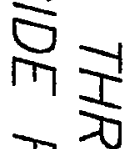

no

界 0

엉ำ

it

WD

$\frac{\pi}{\frac{1}{3}}$

勇立

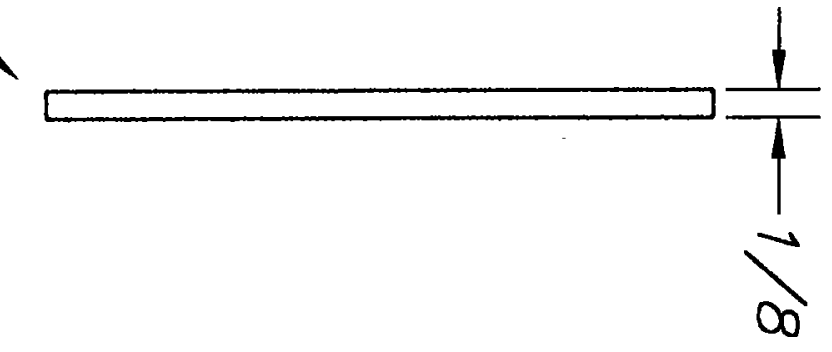


$N$
$D$
0
0
0

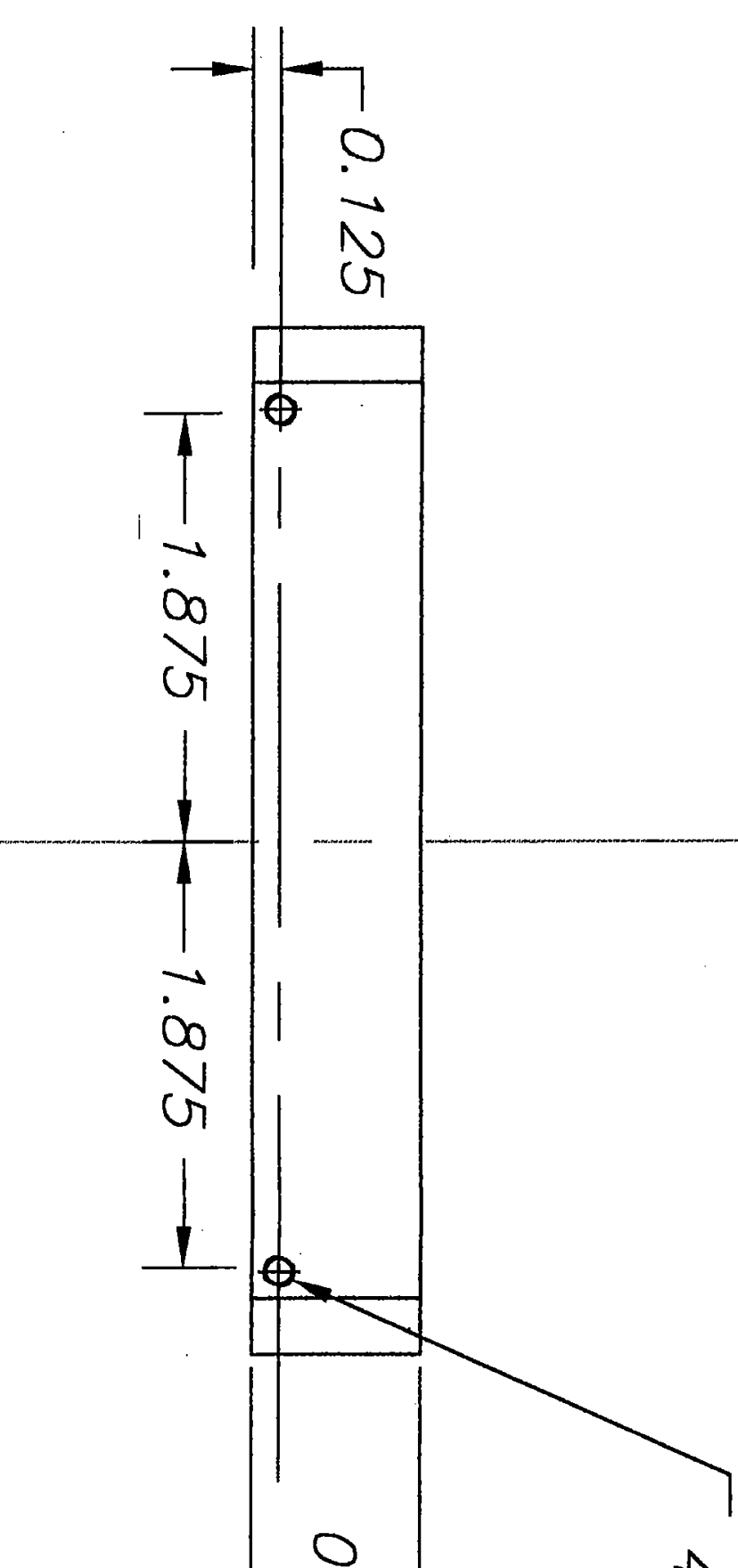

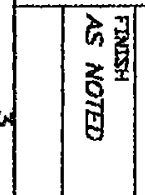

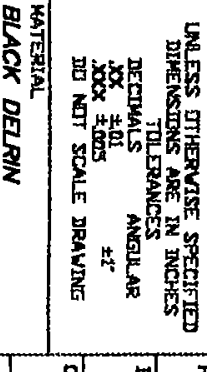

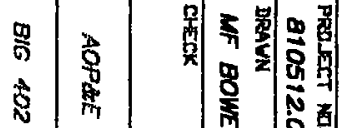

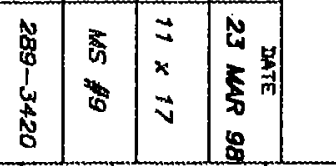

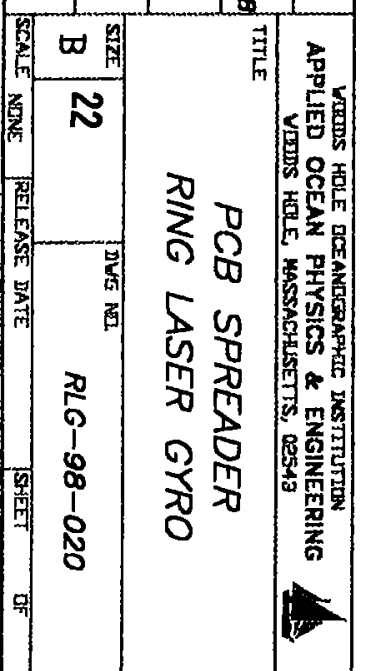

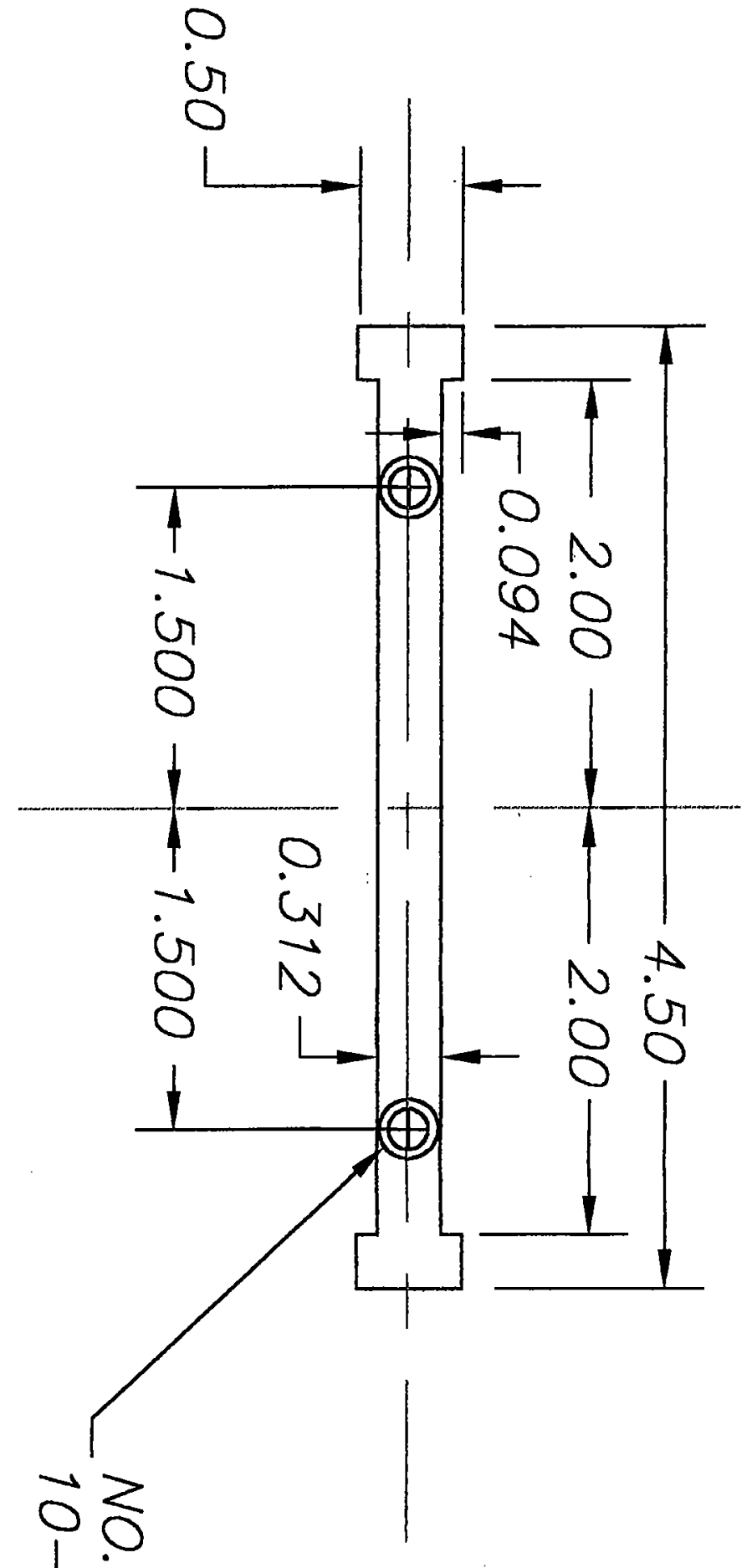

$\begin{array}{cc}0 & 0 \delta \\ 0 & 1 \\ 0 & N N\end{array}$

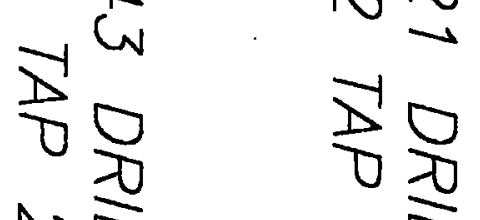

N采 N

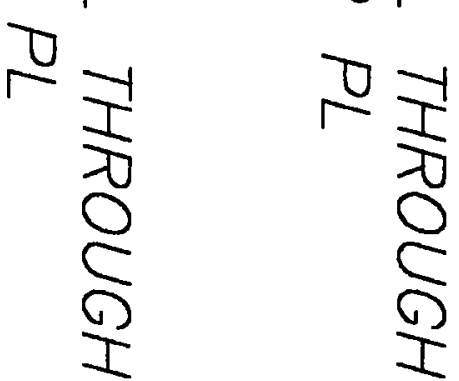




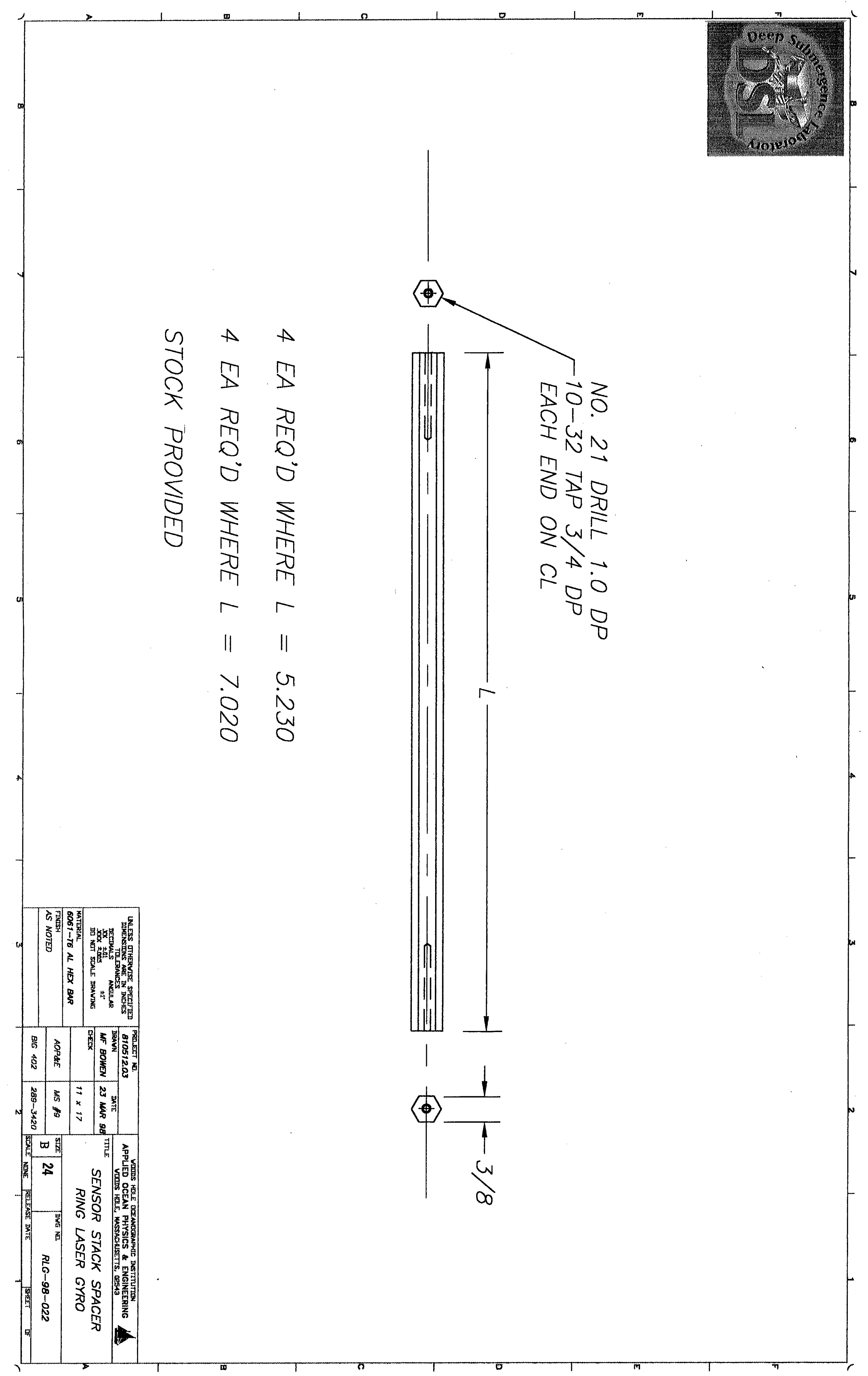



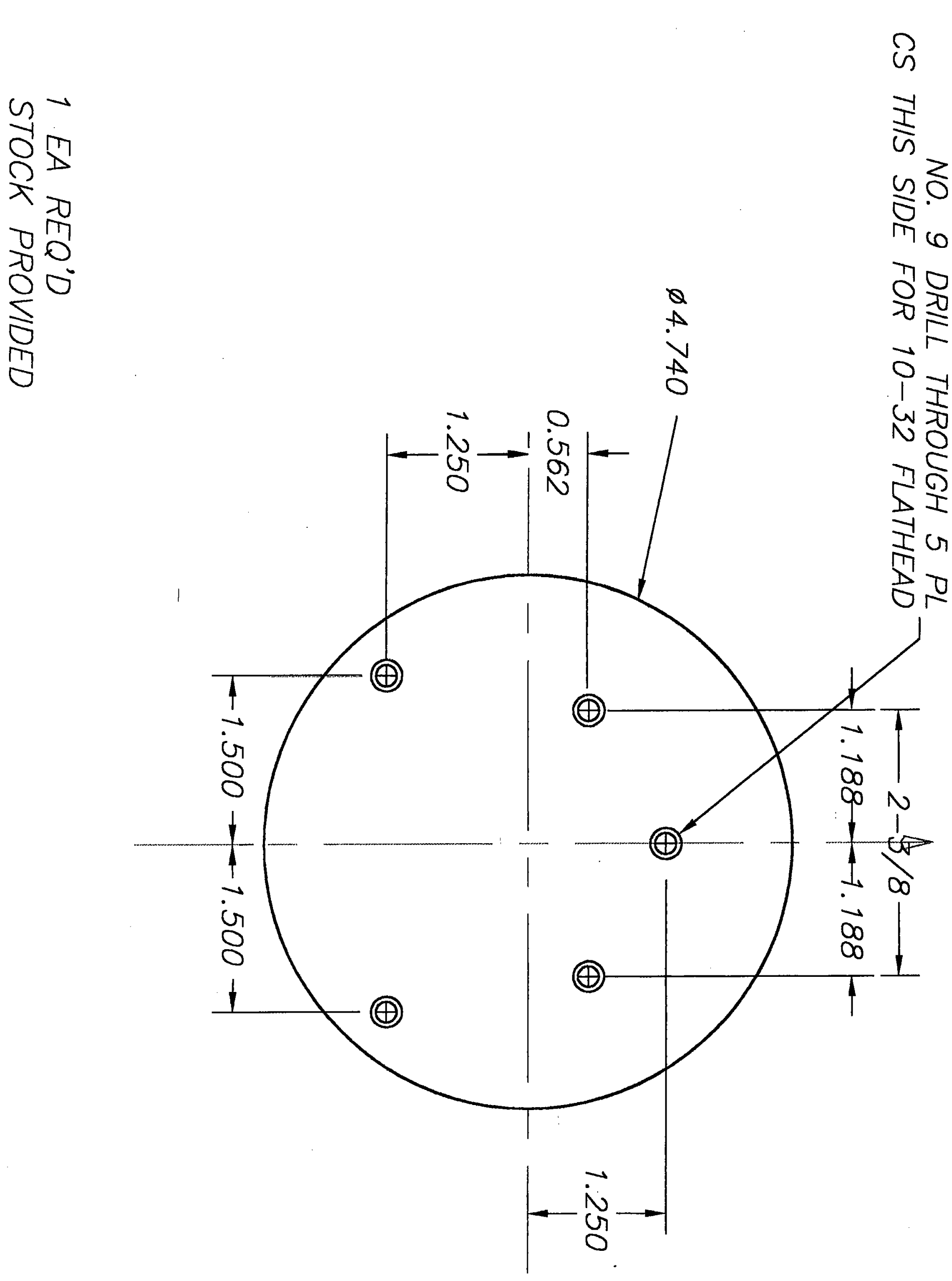

品

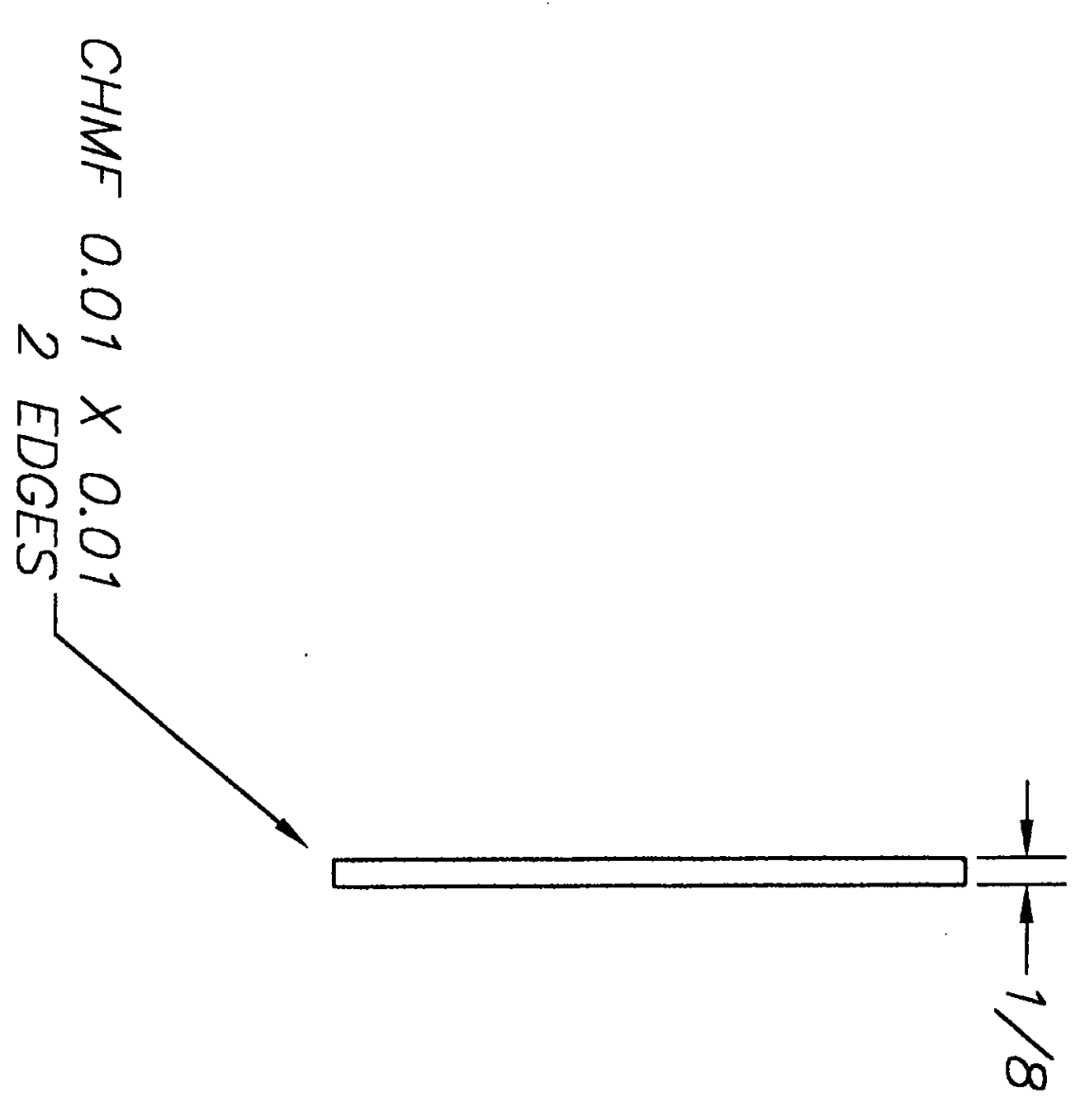




\section{DOCUMENT LIBRARY}

Distribution List for Technical Report Exchange - July 1998

University of California, San Diego

SIO Library $0175 \mathrm{C}$

9500 Gilman Drive

La Jolla, CA 92093-0175

Hancock Library of Biology \& Oceanography

Alan Hancock Laboratory

University of Southern California

University Park

Los Angeles, CA 90089-0371

Gifts \& Exchanges

Library

Bedford Institute of Oceanography

P.O. Box 1006

Dartmouth, NS, B2Y 4A2, CANADA

NOAA/EDIS Miami Library Center

4301 Rickenbacker Causeway

Miami, FL 33149

Research Library

U.S. Army Corps of Engineers

Waterways Experiment Station

3909 Halls Ferry Road

Vicksburg, MS 39180-6199

Marine Resources Information Center

Building E38-320

MIT

Cambridge, MA 02139

Library

Lamont-Doherty Geological Observatory

Columbia University

Palisades, NY 10964

Library

Serials Department

Oregon State University

Corvallis, OR 97331

Pell Marine Science Library

University of Rhode Island

Narragansett Bay Campus

Narragansett, RI 02882

Working Collection

Texas A\&M University

Dept. of Oceanography

College Station, TX 77843
Fisheries-Oceanography Library

151 Oceanography Teaching Bldg.

University of Washington

Seattle, WA 98195

Library

R.S.M.A.S.

University of Miami

4600 Rickenbacker Causeway

Miami, FL 33149

Maury Oceanographic Library

Naval Oceanographic Office

Building 1003 South

1002 Balch Blvd.

Stennis Space Center, MS, 39522-5001

Library

Institute of Ocean Sciences

P.O. Box 6000

Sidney, B.C. V8L 4B2

CANADA

National Oceanographic Library

Southampton Oceanography Centre

European Way

Southampton SO14 3ZH

UK

The Librarian

CSIRO Marine Laboratories

G.P.O. Box 1538

Hobart, Tasmania

AUSTRALIA 7001

Library

Proudman Oceanographic Laboratory

Bidston Observatory

Birkenhead

Merseyside L43 7 RA

UNITED KINGDOM

IFREMER

Centre de Brest

Service Documentation - Publications

BP 7029280 PLOUZANE

FRANCE 


\begin{tabular}{|c|c|c|}
\hline $\begin{array}{l}\text { REPORT DOCUMENTATION } \\
\text { PAGE }\end{array}$ & $\begin{array}{ll}\text { 1. REPORT NO. WHOI-98-15 } & \\
& \text { WHO }\end{array}$ & 3. Recipient's Accession No. \\
\hline \multirow{2}{*}{\multicolumn{2}{|c|}{$\begin{array}{l}\text { 4. Title and Subtitle } \\
\text { Ultimate Ocean Depth Packaging for a Digital Ring Laser Gyroscope }\end{array}$}} & $\begin{array}{l}\text { 5. Report Date } \\
\text { July } 30,1998\end{array}$ \\
\hline & & 6. \\
\hline \multicolumn{2}{|l|}{ 7. Author(s) M. F. Bowen } & $\begin{array}{l}\text { 8. Performing Organization Rept. No. } \\
\text { WHOI-98-15 }\end{array}$ \\
\hline \multicolumn{2}{|c|}{ 9. Performing Organization Name and Address } & 10. Project/Task/Work Unit No. \\
\hline \multicolumn{2}{|c|}{$\begin{array}{l}\text { Woods Hole Oceanographic Institution } \\
\text { Woods Hole, Massachusetts } 02543\end{array}$} & $\begin{array}{l}\text { 11. Contract(C) or Grant(G) No. } \\
\text { (C) OCE-9710512 } \\
\text { (G) }\end{array}$ \\
\hline \multicolumn{2}{|c|}{ National Science Foundation } & $\begin{array}{l}\text { 13. Type of Report \& Period Covered } \\
\text { Technical Report }\end{array}$ \\
\hline & & 14. \\
\hline
\end{tabular}

\section{Supplementary Notes}

This report should be cited as: Woods Hole Oceanog. Inst. Tech. Rept., WHOI-98-15

\section{Abstract (Limit: 200 words)}

A Honeywell GG1320AN Digital Ring Laser Gyroscope (RLG), typically an aviation sensor, has been adapted for use as part of a navigation package rated to ocean depths of 6,000 meters. Researchers and engineers at the Deep Submergence Laboratory (DSL) of the Woods Hole Oceanographic Institution (WHOI) designed a high-density instrument package around the basic RLG. The integrated instrument is modular and field serviceable. It includes a chassis, housing, a Crossbow 6-axis dynamic measurement unit (DMU), battery backup, power regulation, support circuitry and robust interfaces. A pressure-proof titanium case and non-corroding accessories ensure that the RLG will remain unaffected by prolonged immersion in seawater. Associated mounting bracketry allow the housing to be axially registered alongside the navigation suites of various deep diving WHOI assets, or with any host platform capable of carrying a 25 pound payload. Primary RLG platforms will be the manned deep submergence vehicle ALVIN, the unmanned remotely operated vehicle JASON, and the unmanned autonomous vehicle ABE. As an extremely accurate yaw rate measuring device, the RLG will provide navigation data far more reliable and precise that has been available to scientists in the past. The WHOI RLG has been used successfully on one JASON cruise.

17. Document Analysis a. Descriptors
UUV
DSV
Gyro

b. Identifiers/Open-Ended Terms 